Aus dem Institut für Herz- und Kreislaufphysiologie

(Prof. Dr. med. D. M. Katschinski)

im Zentrum Physiologie und Pathophysiologie

der Medizinischen Fakultät der Universität Göttingen

\title{
Die Reorganisation des Aktinzytoskeletts in Hypoxie: Neue Erkenntnisse über die Rolle von ArhGAP29
}

\author{
INAUGURAL-DISSERTATION \\ zur Erlangung des Doktorgrades \\ der Medizinischen Fakultät der \\ Georg-August-Universität zu Göttingen
}

vorgelegt von

Johannes Peters

aus

Frechen

Göttingen 2019 
Dekan:

Referent/in:

Ko-Referent/in:

Drittreferent/in:

Datum der mündlichen Prüfung:
Prof. Dr. H. K. Kroemer

Prof. Dr. Dörthe Katschinski

Prof. Dr. Susanne Lutz

Prof. Dr. Thomas Meyer

22.08.2019 
Hiermit erkläre ich, die Dissertation mit dem Titel "Die Reorganisation des Aktinzytoskeletts in Hypoxie: Neue Erkenntnisse über die Rolle von ArhGAP29" eigenständig angefertigt und keine anderen als die von mir angegebenen Quellen und Hilfsmittel verwendet zu haben.

Göttingen, den 12.02.2019

Johannes Peters 


\section{Inhaltsverzeichnis}

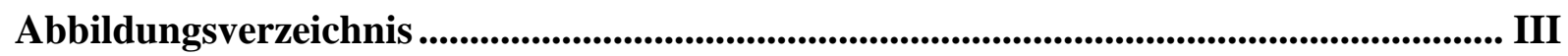

Tabellenverzeichnis ....................................................................................................... III

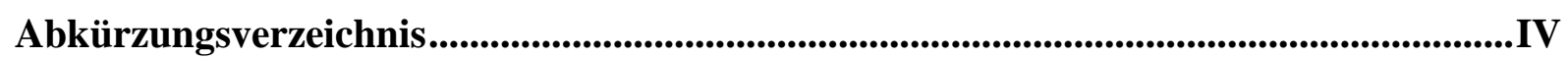

1 Einleitung............................................................................................................................... 1

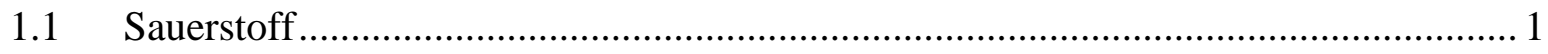

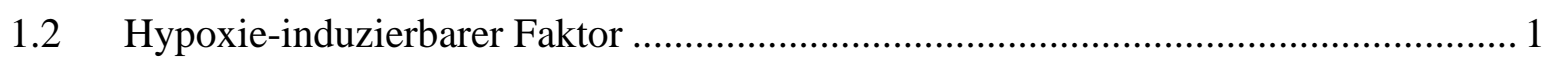

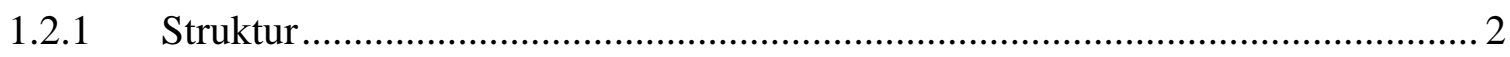

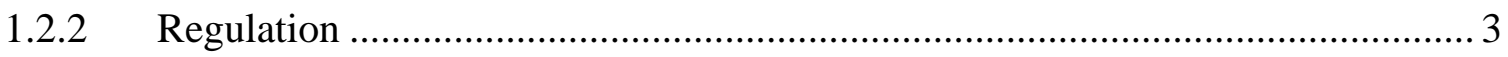

1.3 PHD-Enzyme als zelluläre Sauerstoffsensoren .................................................... 5

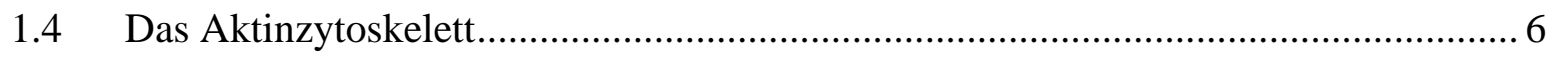

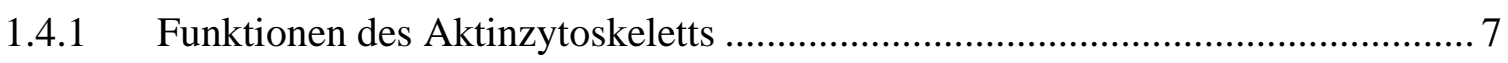

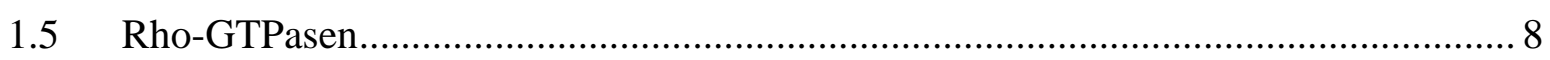

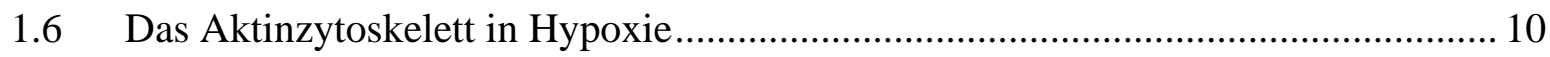

1.6.1 Regulation des Aktinzytoskeletts in Hypoxie ................................................ 11

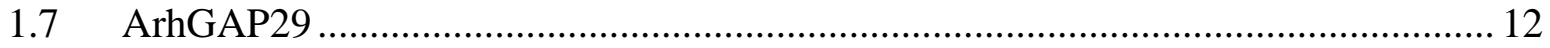

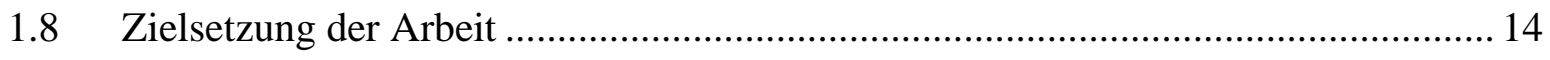

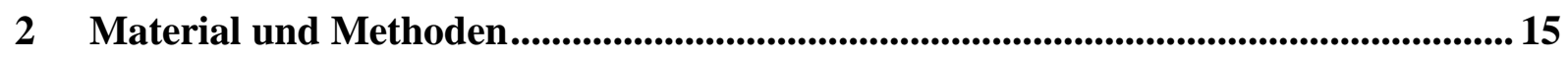

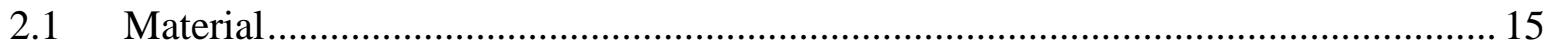

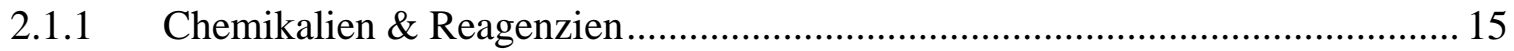

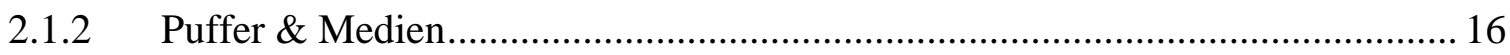

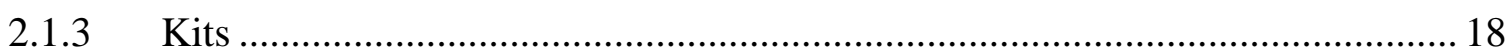

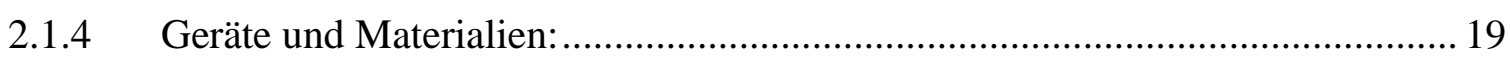

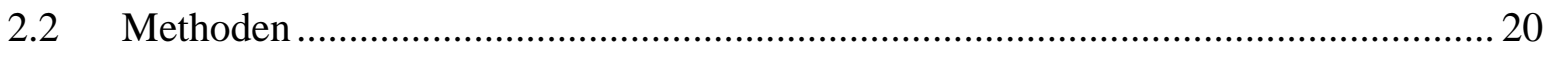

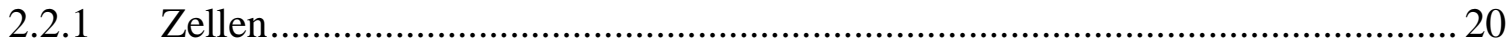

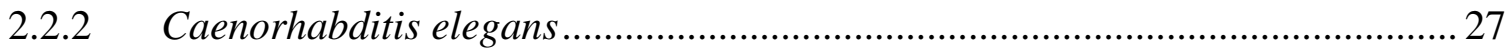

2.2.3 Verwendete Computerprogramme ................................................................ 28

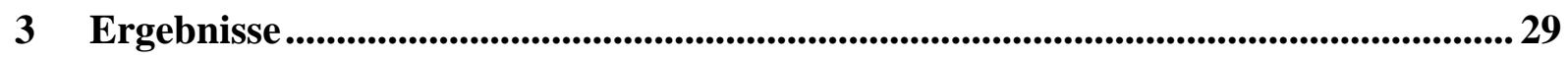

3.1 Regulation von GAPs und GEFs in Hypoxie .................................................. 29

3.2 Zeitliche Dynamik der Genexpression von ArhGAP29 ............................................ 32

3.3 Etablierung eines ArhGAP29-knock-downs in L929-Fibroblasten ........................... 33

3.4 Veränderungen der Zellmorphologie in ArhGAP29-knock-down-Zellen ................. 34

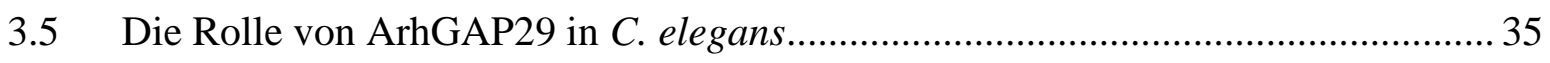

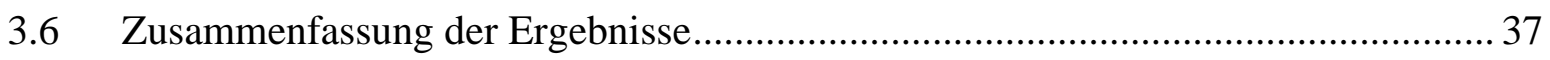




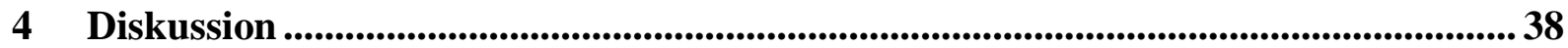

4.1 Die hypoxische Induktion von ArhGAP29 ist abhängig von HIF-1 $\alpha$...................... 39

4.2 ArhGAP29-knock-down-Zellen zeigen morphologische Veränderungen ................. 40

4.3 ArhGAP29 in mehrzelligen Organismen ......................................................... 41

4.4 Die Rolle von ArhGAP29 in klinisch relevanten Pathologien ................................ 42

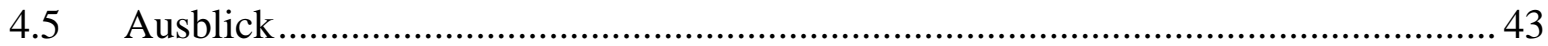

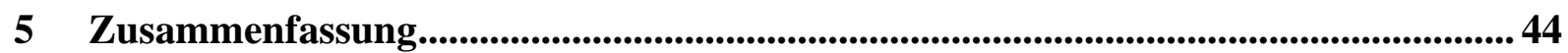

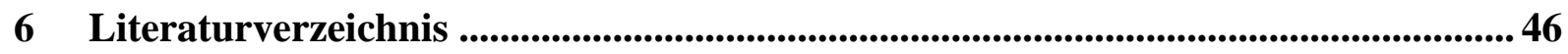




\section{Abbildungsverzeichnis}

Abb. 1: Aufbau von HIF-1 $\alpha$

Abb. 2: Regulation von HIF-1 $\alpha$

Abb. 3: Systematik der kleinen G-Proteine 9

Abb. 4: Regulation der Rho-GTPasen $\quad 10$

Abb. 5: RhoA vermittelt die Hypoxie-induzierte Inaktivierung von Cofilin 12

Abb. 6: ArhGAP29 als Effektorprotein von Rap1 13

Abb. 7: Veränderung der Genexpression Rho-regulierender Proteine in Hypoxie 30

Abb. 8: Induktion von ArhGAP29-mRNA in C2C12-Myoblasten und in L929-Fibroblasten

nach DMOG-Behandlung 30

Abb. 9: Hypoxie und DMOG-Behandlung induzieren ArhGAP29 auf Proteinebene; die hypoxische Induktion von ArhGAP29 erfolgt HIF-1 $\alpha$-abhängig 32

Abb. 10: Hypoxische Induktion von ArhGAP29 im Zeitverlauf 33

Abb. 11: Knock-down von ArhGAP29 in L929-Zellen 34

Abb. 12: Morphologische Veränderungen in L929-Fibroblasten mit ArhGAP29-knock-down

Abb. 13: ArhGAP 29 in C. elegans 36

Abb. 14: Signalweg von ArhGAP29 und RhoA in Hypoxie 40

\section{Tabellenverzeichnis}

Tabelle 1: Verwendete Plasmidvektoren für den ArhGAP29-knock-down 21

Tabelle 2: Übersicht der benutzten primären und sekundären Antikörper 25

Tabelle 3: Übersicht der verwendeten Primer 27

Tabelle 4: Thermalprofil der qRT-PCR 27

Tabelle 5: Übersicht der veränderten Genexpression Rho-regulierender Proteine 31 


\section{Abkürzungsverzeichnis}

A

a.u.

ADP

ArhGAP29 Rho-GTPase aktivierendes Protein 29

ARNT aryl hydrocarbon receptor nuclear translocator

ATP Adenosintriphosphat

BSA bovines Serumalbumin

Cdc42 Protein der Rho-Subfamilie (cell division control protein 42 homolog)

cDNA komplementäre DNA (complementary DNA)

C. elegans Caenorhabditis elegans

CBP CREB-binding-protein

ChIP-Assay Chromatin-Immunopräzipitations-Assay

CREB $\quad$ cAMP response element-binding protein

DAPI 4',6'-Diamidino-2-phenylindol

DEPC Diethylpyrocarbonat

DMEM Dulbecco's modified Eagle's Serum

DMOG Dimethyloxaloylglycin

DMSO Dimethylsulfoxid

DNA Desoxyribonukleinsäure (deoxyribonucleic acid)

dNTP Desoxyribonukleosidtriphosphat

DTT Dithiothreitol

EDTA Ethylendiamintetraacetat

EGL-9 egg laying abnormal 9

EMSA electrophoretic mobility shift assay

Epo Erythropoietin

EZM Extrazellulärmatrix

F-Aktin filamentöses Aktin

FCS fetales Kälberserum (fetal calf serum) 
FIH factor inhibiting HIF

FITC Fluoresceinthiocyanat

G-Aktin globuläres Aktin

GAP GTPase-aktivierendes Protein

GEF Guanin-Nukleotid Austausch Faktor (guanine nucleotide exchange factor)

GDI Guanin-Nukleotid-Dissoziations-Inhibitor

GDP Guanosindiphosphat

GLUT1 Glukose-Transporter1

GTP Guanosintriphosphat

HIF Hypoxie-induzierbarer Faktor

HRE hypoxia-response-element

HRP Meerrettichperoxidase (horseradish peroxidase)

iNOS induzierbare NO-Synthase

kd Herrunterregulierung eines Gens (knock-down)

kDa kilo Dalton

Km Michaelismentenkonstante, Kenngröße für enzymatische Reaktion

LB-Medium Nährmedium zur Kultivierung von Bakterien (lysogeny broth)

LKGS Lippen-Kiefer-Spalte mit oder ohne Gaumenbeteiligung

MLK Myosin-Leichtketten

mRNA Boten-RNA (messenger RNA)

ms12 Haushaltsgen in Mäusen (minisatellites detected by probe MMS12)

NLS nuclear localiztation signal

ODDD oxygen-dependent degradation domain

PAGE Polyacrylamid-Gelelektrophorese

PARG1 Protein-tyrosin Phosphatase-assoziiertes-Rho-GTPase-aktivierendes-Protein-1 (Synonym für ArhGAP29 verwendet)

PAS Per/Arnt/Sim-Domäne

PBS Phosphatgepufferte Salzlösung (phosphat buffered saline)

PCR Polymerase-Kettenreaktion

Pen Penicillin 


\begin{tabular}{|c|c|}
\hline PFA & Paraformaldehyd \\
\hline $\mathrm{pH}$ & $\begin{array}{l}\text { negativer dekadischer Logarithmus der Wasserstoffionenkonzentration (pondus } \\
\text { hydrogenii) }\end{array}$ \\
\hline PHD & Prolyl-4-Hydroxylase-Domäne-Proteine \\
\hline pVHL & von-Hippel-Lindau-Tumorsuppressorprotein \\
\hline qRT-PCR & $\begin{array}{l}\text { Quantitative Echtzeit-Polymerase-Kettenreaktion (quantitative real-time } \\
\text { polymerase chain reaction) }\end{array}$ \\
\hline $\mathrm{Rab}$ & Protein der Ras-Superfamilie (ras-related in brain) \\
\hline Rac1 & Protein der Rho-Subfamilie (ras-related C3 botulinum toxin substrate 1) \\
\hline Radil & ras-association and dilute domain-containing protein \\
\hline Rap1/2 & Ras-verwandtes Protein $1 / 2$ (Ras related protein $1 / 2$ ) \\
\hline Ras & Protoonkogen, codiert für kleines G-Protein (rat sarcoma) \\
\hline Rasip1 & Ras-interagierendes Protein 1 \\
\hline Rho & Proteingruppe der Ras-Superfamilie (ras-homologue) \\
\hline RNA & Ribonukleinsäure (ribonucleic acid) \\
\hline ROCK & Rho-associated coiled-coil-forming protein kinase \\
\hline rpm & Umdrehungen pro Minute (revolutions per minute) \\
\hline RT & Raumtemperatur \\
\hline SDS & Natriumdodecylsulfat (sodium dodecyl sulfate) \\
\hline SEM & Standardfehler (standard error of the mean) \\
\hline shRNA & RNA-Molekül mit Haarnadelstruktur (small hairpin $R N A$ ) \\
\hline siRNA & small-interfering $R N A$ \\
\hline Spv-1 & $\begin{array}{l}\text { Homologes Gen zu ArhGAP29 in C. elegans (Spermatheca physiology variant- } \\
\text { 1) }\end{array}$ \\
\hline Strep & Streptomycin \\
\hline TAD & Transaktivierungsdomäne \\
\hline Tris & Tris-(hydroxymethyl-)aminomethan \\
\hline $\mathrm{U}$ & Enzymeinheit (unit) \\
\hline VEGF & vascular endothelial growth factor \\
\hline
\end{tabular}


Einleitung

\section{Einleitung}

\subsection{Sauerstoff}

Molekularer Sauerstoff spielt in allen mehrzelligen Organismen eine entscheidende Rolle für die Energiegewinnung. In der Atmungskette läuft mithilfe von Sauerstoff eine fraktionierte exotherme Reaktion ab, durch die ein Protonengradient an der mitochondrialen Membran aufgebaut wird. Dieser wird von dem Enzym ATP-Synthase zur oxidativen Phosphorylierung, der Synthese von energiereichem ATP aus ADP und Phosphat, genutzt. Das gewonnene ATP kann als universeller Energieträger vielfach in der Zelle genutzt werden, zum Beispiel für aktive Transporter, Muskelkontraktion und Stoffwechselwege. Sauerstoff dient in der Atmungskette als Elektronenakzeptor und ist für deren Aufrechterhaltung essenziell.

Die Aufnahme von Sauerstoff in Säugetieren erfolgt durch Lungenatmung. Das bedeutet, dass der Sauerstoff durch Inspiration in die Lunge gelangt und dort entlang seines Partialdruckgefälles von den Lungenalveolen in das kapilläre Blut diffundiert. Sauerstoffmoleküle werden von den Hämgruppen des Hämoglobins in den Erythrozyten gebunden und über die Blutbahn transportiert. Erst im peripheren Gewebe wird Sauerstoff - wieder durch Unterschiede im Sauerstoffpartialdruck - vom Hämoglobin gelöst und kann zur Zielzelle diffundieren.

Um die physiologischen Funktionen der Zelle auch bei unstetem Sauerstoffangebot zu gewährleisten, gibt es eine Vielzahl von Anpassungsmechanismen. Dafür sind folgende Begriffe voneinander abzugrenzen: Normoxie beschreibt eine angemessene Sauerstoffversorgung, Anoxie ist das völlige Fehlen von Sauerstoff, Hypoxie wird als erhöhter Sauerstoffbedarf im Vergleich zum Sauerstoffangebot definiert. Hypoxie tritt einerseits physiologisch, z. B. im Rahmen der Embryogenese, bei der Wundheilung oder einem Aufenthalt in großen Höhen auf, andererseits auch im pathologischen Kontext, wie etwa bei der Tumorgenese, Myokard- und Hirninfarkten, Herzinsuffizienz oder der arteriellen Verschlusskrankheit.

\subsection{Hypoxie-induzierbarer Faktor}

Kommt es in einer Zelle oder in einem Gewebe zu Hypoxie, werden bestimmte Gene vermehrt exprimiert, um die Zelle auf den Sauerstoffmangel einzustellen und die Sauerstoffversorgung zu verbessern. 


\section{Einleitung}

Mit mehr als 100 identifizierten Zielgenen (Liu et al. 2012) ist der Hypoxie-induzierbare Faktor 1 (HIF-1) der Haupttranskriptionsfaktor zum Erhalt der Sauerstoff-Homöostase unter hypoxischen Bedingungen. HIF-1 induziert u. a. die Expression des Epo-Gens, was zu einer gesteigerten Erythropoese im Knochenmark führt (Wang und Semenza 1993). Weitere von HIF-1 regulierte Zielgene sind der vascular endothelial growth factor (VEGF), die induzierbare NO-Synthase und die Tyrosin-Hydroxylase; der VEGF regt die Angiogenese im Gewebe an (Forsythe et al. 1996), während die induzierbare NO-Synthase (iNOS) eine Gefäßdilatation bewirkt (Melillo et al. 1995) und die Tyrosin-Hydroxylase eine erhöhte Atemfrequenz vermittelt (Norris und Millhorn 1995). Neben einer verbesserten Sauerstoffversorgung des Gewebes durch die oben genannten Mechanismen unterstützt HIF-1 auch die metabolische Umstellung der Zelle auf anaerobe Energiegewinnung mittels Glykolyse. Dies geschieht beispielsweise durch die HIF-1-abhängige Transkription des Glukosetransporter-1 (Glut1)Gens (Ebert et al. 1995). Da HIF-1 $\alpha$ in Hypoxie stabilisiert wird, kommt seine Funktion, wie oben beschrieben, vor allem in hypoxischen Geweben zum Tragen. Es konnte gezeigt werden, dass HIF-1 $\alpha$ in vielen verschiedenen Tumorarten überexprimiert wird (Zhong et al. 1999) und dass es durch eine verminderte Ausbildung von Zell-Zell-Kontakten die Metastasierungswahrscheinlichkeit von Tumoren erhöht (Evans et al. 2007). In Untersuchungen an Mäuseembryonen konnte eine Beteiligung von HIF-1 $\alpha$ an der Embryogenese nachgewiesen werden, es zeigte sich eine erhöhte Genexpression zwischen E8.5 und E9.5. Ein Knock-out von HIF-1 $\alpha$, der unter anderem eine verminderte Expression des VEGF-Gens bedingt, wirkte sich in Mäuseembryonen letal in E11 aus, wobei kardiovaskuläre Malformationen sowie Neuralrohrdefekte auftraten (Iyer et al. 1998).

\subsubsection{Struktur}

HIF-1 ist ein heterodimerer Transkriptionsfaktor, der aus einer $120 \mathrm{kDa}$ schweren HIF-1 $\alpha$-Untereinheit sowie einer 91-94 kDa schweren HIF-1 $\beta$-Untereinheit besteht (auch als Aryl hydrocarbon receptor nuclear translocator (ARNT) bekannt). Beide Untereinheiten sind basic-helix-loop-helix-(bHLH)-Proteine, die jeweils zwei Per/Arnt/Sim-(PAS)- Domänen besitzen (Wang et al. 1995), welche an der Bindung von DNA und der Dimerisierung der HIF1-Untereinheiten beteiligt sind (s. Abb. 1) (Reisz-Porszasz et al. 1994). Mithilfe der bHLHDomäne bindet HIF-1 $\alpha$ sogenannte hypoxia response elements (HREs), spezifische DNASequenzen (5'-G/ACGTG-3'), die in regulierenden Elementen von HIF-Zielgenen liegen (Wang et al. 1995). Des Weiteren vermitteln zwei Transaktivierungsdomänen (TADs) die Bindung von Transkriptionskofaktoren, wovon sich eine Transaktivierungsdomäne am 
N-Terminus (N-TAD) und eine am C-Terminus (C-TAD) des HIF-1 $\alpha$-Proteins befindet (Jiang et al. 1997).

Über die oxygen-dependent degradation (ODD)- Domäne wird der Abbau von HIF-1 $\alpha$ unter normoxischen Bedingungen reguliert. Hier hydroxylieren Prolyl-4-HydroxylaseDomäne-Enzyme (PHDs) sauerstoffabhängig die Prolinreste Pro ${ }^{402}$ und Pro $^{564}$ und initiieren so den proteasomalen Abbau des Proteins (Ivan et al. 2001; Jaakkola et al. 2001) (siehe Kapitel $1.3)$.

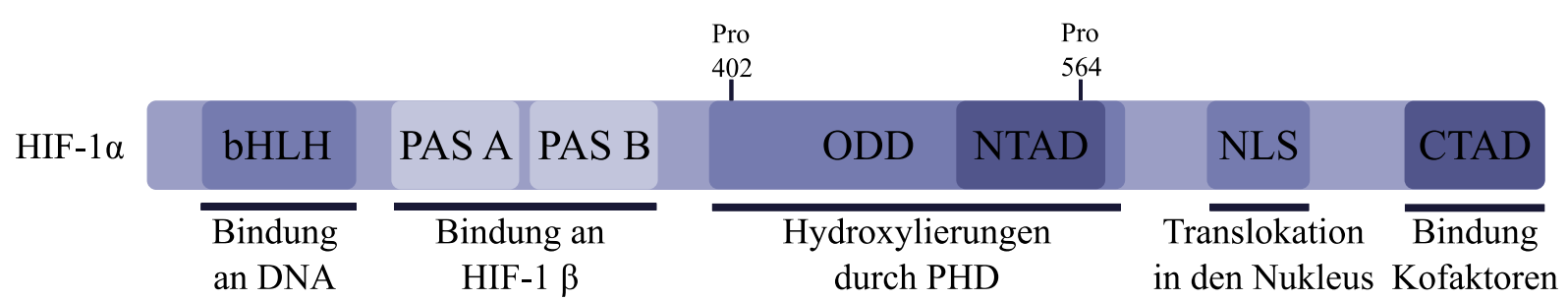

Abb. 1: Aufbau von HIF-1 $\alpha$. Die schematische Grafik zeigt die $\alpha$-Untereinheit des HIF-1-Transkriptionsfaktors mit seinen funktionellen Domänen und deren Eigenschaften. Die kritischen Prolinreste sind ebenfalls eingezeichnet. Abkürzungen: bHLH (basic helix-loop-helix-domain), PAS (Per/ARNT/Sim)-Domäne, ODD (oxygen dependent degradation)-Domäne, NTAD (N-terminale Transaktivierungsdomäne), NLS (nuclear localisation signal), CTAD (C-terminale Transaktivierungsdomäne), Pro (Prolinrest). Modifiziert nach Rocha 2007.

Neben HIF-1 $\alpha$ gibt es mit HIF-2 $\alpha$ und HIF-3 $\alpha$ zwei weitere sauerstoffabhängige Isoformen. HIF-2 $\alpha$ hat bezüglich Struktur und Funktion große Ähnlichkeiten mit HIF-1 $\alpha$, wird allerdings nicht wie HIF-1 $\alpha$ ubiquitär, sondern vorwiegend in vaskulären Endothelzellen sowie in Lunge, Herz und Leber exprimiert (Ema et al. 1997; Wiesener et al. 2003). Auch das Spektrum der Zielgene zeigt große Überschneidungen, jedoch ist HIF-2 $\alpha$ nicht an der Expression von Enzymen des glykolytischen Stoffwechsels beteiligt (Hu et al. 2003). Die Rolle von HIF-3a ist noch nicht genau geklärt.

\subsubsection{Regulation}

Der HIF-1-Signalweg wird über den Abbau bzw. die Stabilisierung der konstitutiv exprimierten HIF-1 $\alpha$-Untereinheit (s. Abb. 2) und an weiteren Punkten des Wirkmechanismus reguliert.

Liegt in einer Zelle ausreichend molekularer Sauerstoff vor, wird HIF-1 $\alpha$ durch PHDs an den Prolinresten Pro $^{402}$ und Pro ${ }^{564}$ in der ODD-Domäne hydroxyliert. In dieser Reaktion fungiert Sauerstoff als einer von mehreren benötigten Kofaktoren. Das von-Hippel-LindauTumorsuppressorprotein (pVHL), das Teil eines E3-Ubiquitin-Ligasekomplexes ist, erkennt die Hydroxylierungen, bindet an HIF-1 $\alpha$ und vermittelt eine Polyubiquitinierung, die HIF-1 $\alpha$ für den proteasomalen Abbau markiert (Maxwell et al. 1999; Yu et al. 2001). 


\section{Einleitung}

Dass eine Störung dieses Signalweges eine klinische Relevanz hat, zeigt sich beispielsweise beim von-Hippel-Lindau-Syndrom, bei dem es zu einer autosomal dominant vererbten Mutation des von-Hippel-Lindau-Tumorsuppressorgens kommt. Durch eine fehlerhafte Faltung des Proteins pVHL bleibt die oben genannte Polyubiquitinierung aus, und es kommt zu einer durchgehenden normoxischen Stabilisierung von HIF-1 $\alpha$. Diese führt zur Ausbildung von Hämangioblastomen im zentralen Nervensystem und in der Retina. Auch eine Assoziation mit Nierenzellkarzinomen und Phäochromozytomen ist bekannt (Latif et al. 1993; Kaelin 2002).

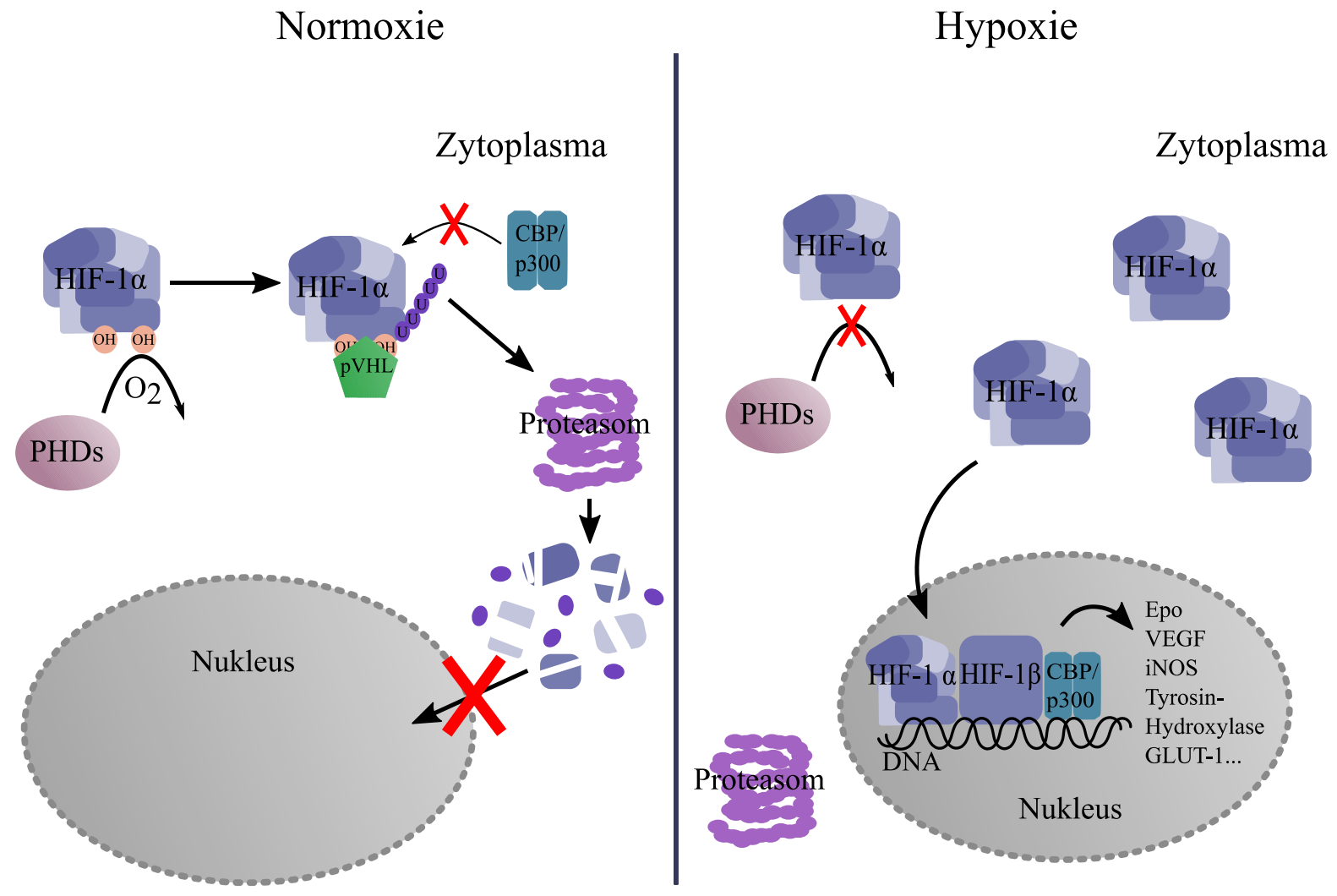

Abb. 2: Regulation von HIF-1 $\alpha$. In Normoxie wird die HIF-1 $\alpha$-Untereinheit sauerstoffabhängig von den PHDs an Pro402 und Pro564 hydroxyliert. Das pVHL erkennt die Hydroxylierungen und vermittelt eine Polyubiquitinierung, die zum proteasomalen Abbau von HIF-1 $\alpha$ führt. Unter hypoxischen Bedingungen kann die Hydroxylierungsreaktion nicht stattfinden, HIF-1 $\alpha$ akkumuliert in der Zelle, transloziert in den Nukleus und dimerisiert dort mit der HIF-1 $\beta$-Untereinheit. Zusammen mit Transkriptionskofaktoren wie CBP und p300 werden die HIF-Zielgene abgelesen. Abkürzungen: CBP (CREB-binding-protein), OH (Hydroxylgruppe), pVHL (vonHippel-Lindau-Protein), U (Ubiquitin).

Unter hypoxischen Bedingungen können die Prolinreste in der ODD-Domäne von HIF-1 $\alpha$ aufgrund von Mangel an Sauerstoffmolekülen nicht hydroxyliert werden, es wird somit stabilisiert und akkumuliert in der Zelle. Im Folgenden transloziert HIF-1 $\alpha$ mithilfe des nuclear localisation signal (NLS) vom Zytoplasma in den Zellkern und dimerisiert mit der HIF-1 $\beta$ Untereinheit (ARNT). Nach der Rekrutierung von Transkriptionskofaktoren wie CREBbinding-protein (CBP) und p300 erfolgt durch den HIF-1-Transkriptionskomplex die Transkription der Zielgene, um adaptive zelluläre Prozesse unter Sauerstoffmangel einzuleiten 


\section{Einleitung}

(Kallio et al. 1998). Die Kofaktoren CBP/p300 sind Acetyltransferasen, die durch Acetylierung von Histonen die Chromatinstruktur auflockern und die Anlagerung des Transkriptionskomplexes an die Zielgene vereinfachen. Sie sind bei der Transkription diverser Gene involviert (Schiltz et al. 1999).

Die Bindung von $\mathrm{CBP} / \mathrm{p} 300$ an HIF-1 $\alpha$ wird unter normoxischen Bedingungen wiederum verhindert, indem eine sauerstoffabhängige Asparaginylhydroxylase einen Asparaginrest in der CTAD $\left(\mathrm{Asn}^{803}\right)$ des HIF-1 $\alpha$ Proteins hydroxyliert. Dieses Enzym wurde von seinen Entdeckern Mahon et al. daher Factor inhibiting HIF-1 (FIH-1) genannt (Mahon et al. 2001; Lando et al. 2002). Somit bewirken verschiedene Sauerstoff-abhängige Hydroxylierungen von HIF-1 $\alpha$ sowohl eine proteasomale Degradation als auch eine Verminderung der Transkriptionsaktivität.

\subsection{PHD-Enzyme als zelluläre Sauerstoffsensoren}

Die bereits erwähnten Hydroxylierungen an den kritischen Prolinresten Pro ${ }^{402}$ und Pro ${ }^{564}$ werden durch die PHDs vermittelt, die zur Gruppe der Eisen- und 2-Oxoglutaratabhängigen Dioxygenasen gehören. Neben Eisen, 2-Oxoglutarat und Ascorbat, das als Antioxidans des zweiwertigen Eisens fungiert (Myllyla et al. 1978), spielt molekularer Sauerstoff eine wichtige Rolle als Kosubstrat der Hydroxylierungsreaktion. Die PHD-Enzyme haben einen Km-Wert von 230-250 $\mu \mathrm{M}$ für Sauerstoff, welcher geringfügig höher als der atmosphärische Sauerstoffpartialdruck auf Meereshöhe ist (Hirsila et al. 2003). Das bedeutet, dass PHDEnzyme bereits auf leichte Änderungen im Sauerstoffangebot mit deutlichen Änderungen in der Enzymaktivität reagieren, was sie zu effektiven und sensiblen Sauerstoffsensoren der Zelle macht.

Aufgrund der zahlreichen benötigten Kofaktoren ergeben sich neben einem Mangel an Sauerstoff weitere Möglichkeiten, die Aktivität der PHDs zu verringern. So können zum Beispiel die 2-Oxoglutarat-Analoga N-Oxalylglycin (N-OG) und Dimethyloxalylglycin (DMOG) durch die Inhibierung der PHD-Aktivität eine normoxische HIF-1 $\alpha$ Stabilisierung in vitro und in vivo bewirken. Für diese Arbeit wurde DMOG als PHD-Inhibitor in vitro verwendet.

Innerhalb der Enzymgruppe der PHDs sind im Menschen drei Isoformen (PHD1, PHD2 und PHD3) bekannt, die sich in ihrer katalytischen Reaktion ähnlich sind, sich jedoch in Zelllokalisation, Expressionsort und hypoxischer Induktion unterscheiden. Die drei PHDFormen kommen zwar in allen Geweben vor, jedoch in unterschiedlicher Ausprägung. PHD1 


\section{Einleitung}

zeigt besonders hohe Level in Hodengewebe, PHD2 ist in allen Geweben zu finden und PHD3 findet sich vorrangig in Herzmuskelzellen (Lieb et al. 2002; Cioffi et al. 2003). Von Metzen et al. konnte gezeigt werden, dass PHD1 im Nukleus, PHD2 vor allem im Zytoplasma und PHD3 in beiden Kompartimenten zu finden ist (Metzen et al. 2003).

PHD2 ist die ubiquitär vorliegende Isoform der HIF-Hydroxylasen und ist hauptsächlich für die normoxische Hydroxylierung von HIF-1 $\alpha$ zuständig. Da PHD2 ein HIF-Zielgen ist wird es unter hypoxischen Bedingungen induziert und sorgt im Sinne eines negativen Feedbackloops im Falle einer Reoxygenierung für den raschen Abbau von HIF-1 $\alpha$ (Berra et al. 2003). PHD3 zeigt ebenfalls eine HIF-abhängige Induktion, besitzt jedoch eine höhere Aktivität gegen HIF$2 \alpha$ als gegen HIF-1 $\alpha$ (Appelhoff et al. 2004). PHD1 unterliegt keiner hypoxischen Induktion (Willam et al. 2006).

\subsection{Das Aktinzytoskelett}

Jede eukaryotische Zelle besitzt ein Zytoskelett, das aus drei Elementen besteht. Man unterscheidet Mikrotubuli, Intermediärfilamente und Aktinfilamente. In dieser Arbeit wird insbesondere der Einfluss von Hypoxie auf das Aktinzytoskelett näher untersucht. Mit einer Dicke von ca. $7 \mathrm{~nm}$ bildet es die dünnsten Filamente des Zytoskeletts aus (Holmes et al. 1990). Es unterliegt einer ständigen, dynamischen Aneinanderreihung und Dissoziation von globulären Aktinuntereinheiten (G-Aktin), die sich zu filamentösem Aktin (F-Aktin) verbinden. So kann das Aktinzytoskelett zu Form, Stabilität, Migration und weiteren Funktionen der Zelle beitragen (Pollard und Cooper 2009).

Sechs Aktinisoformen sind bei Säugetieren bekannt, die sich nur minimal in ihrer Aminosäuresequenz unterscheiden, jedoch bestehen Hinweise auf Unterschiede in Expressionsmuster und Funktion. Die $\alpha$-Isoformen ( $\alpha_{\text {skeletal }}, \alpha_{\text {cardiac }}$ und $\left.\alpha_{\text {smooth }}\right)$ sowie das $\gamma_{\text {smooth- }}$ Aktin sind beispielsweise an den kontraktilen Einheiten von Muskelzellen beteiligt, während

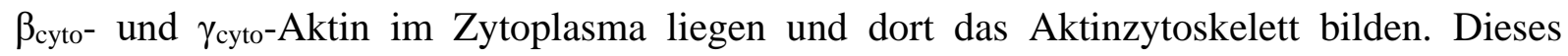
organisiert sich in Form von Bündeln, Netzwerken oder dreidimensionalen Gels vorrangig im Zellkortex unterhalb der Plasmamembran (Pollard und Cooper 2009). In Experimenten an Mäusen mit Knock-outs der verschiedenen Aktinisoformen zeigten sich unterschiedlich beeinträchtige Phänotypen von Tod in der Embryonalphase bis zu lebensfähigen Mäusen mit beeinträchtigter Blutdruckregulation, was unterschiedliche Funktionen der Aktinisoformen nahelegt (Perrin und Ervasti 2010). Es ist zu beachten, dass durchaus weitere Expressionsorte

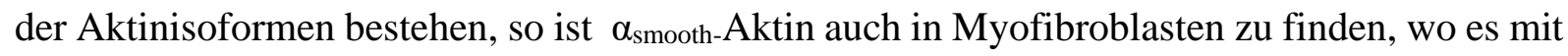




\section{Einleitung}

einem glattmuskulären Aktin-Myosin-Komplex deren Kontraktion vermittelt (Skalli et al. 1989).

In Aktinfilamenten werden die globulären, polaren Untereinheiten immer auf dieselbe Weise durch nichtkovalente Bindungen aneinandergereiht, wodurch sich eine polare Ausrichtung ergibt (Brown und Spudich 1979). Anlagerung und Abbau von Aktinmolekülen findet nur an den zwei Enden des Filaments statt, wobei das schneller wachsende Ende als Plus-Ende und das langsamer wachsende oder abbauende Ende als Minus-Ende definiert ist. G-AktinMoleküle, die sich an ein bestehendes Filament anlagern, haben das energiereiche Nukleotid ATP gebunden, welches nach kurzer Zeit durch Hydrolyse zu ADP umgewandelt wird. Die frei gewordene Energie geht zu einem großen Teil in das Polymer-Netzwerk des F-Aktins über. Infolgedessen verringert sich die Bindungsaffinität der ADP-tragenden Untereinheiten zu den Nachbareinheiten und die Dissoziationswahrscheinlichkeit wird erhöht (Mitchison 1995; Vavylonis et al. 2005). Im Zustand des sogenannten Treadmilling gleichen sich Wachstum am Plus-Ende und Abbau am Minus-Ende genau aus, das Filament behält also eine konstante Länge, schiebt sich aber in Richtung des Plus-Endes vor (Theriot 2000). Dieses Prinzip der ständigen Neuorganisation der Aktinfilamente erhöht die Flexibilität der Zelle im Raum und erlaubt es ihr, schnell auf Änderungen in der Umgebung zu reagieren. Reguliert wird die Aktindynamik durch eine Vielzahl aktinbindender Proteine.

\subsubsection{Funktionen des Aktinzytoskeletts}

Das Aktinzytoskelett hat vielfältige Funktionen. Es gibt beispielsweise der Zelle ihre Form und mechanische Stabilität. Es hält in seinem dichten, membrannahen Netzwerk Membranproteine an ihrem Platz und ist an der Befestigung von Zell-Zell- und Fokalkontakten beteiligt; außerdem wirkt es aktiv bei der Endozytose mit (Robertson et al. 2009). Zusammen mit dem Motorprotein Myosin II können Aktinfilamente mittels ATP-Hydrolyse kontraktile Kräfte sowohl in Muskelzellen, als auch in Nicht-Muskelzellen ausbilden. Kontraktile Aktomyosinbündel in Nicht-Muskelzellen, sogenannte stress fibres, unterliegen mit der Myosin II-ATPase grundsätzlich demselben Kontraktionsprinzip wie Skelett- oder Herzmuskelzellen. Ein weiteres Beispiel für die Ausbildung kontraktiler Kräfte zeigt sich bei der Zytokinese, bei der ein Ring aus Aktin- und Myosin II -Filamenten das Zytoplasma der sich teilenden Zelle einschnürt um zwei Tochterzellen zu bilden (Tojkander et al. 2012).

Das in 1.4 beschriebene Treadmilling ermöglicht es der Zelle, durch gerichteten Aktinfilamentaufbau eine Polarität zu erzeugen. So kann sie blatt- und fingerförmige 


\section{Einleitung}

Vorwölbungen der Zellmembran (Lamellipodien und Filopodien) ausbilden, um die Umgebung zu erkunden oder die ganze Zelle über eine Oberfläche zu bewegen. Dazu erfolgt zusätzlich die Bildung neuer Fokalkontakte, um eine ausreichende Haftung auf dem Untergrund zu gewährleisten. Des Weiteren kommt es zu einer Traktion des hinteren Zellabschnitts mithilfe von kontraktilen stress fibres, um ihn an den vorangehenden Teil heranzuziehen (Pollard und Cooper 2009). Die Zellmigration ist in mehrzelligen Lebewesen essenziell, wie die Einwanderung von Fibroblasten in Wundgebiete und die Migration von Neuralleistenzellen während der Embryonalentwicklung verdeutlichen.

Die Regulation dieser vielseitigen Funktionen des Aktinzytoskeletts wird hauptsächlich durch die Proteinfamilie der Rho-GTPasen bestimmt. Dies sind kleine G-Proteine, die eine zentrale Rolle in vielen regulatorischen Signalwegen einnehmen. Über diese Signalwege beeinflussen sie die Aktivität aktinbindender Proteine und damit unter anderem die Ausbildung von stress fibres.

\subsection{Rho-GTPasen}

Rho (ras homologue) -GTPasen sind kleine, monomere G-Proteine mit einer Molekülmasse von 20-25 kDa. In der übergeordneten Ras-Proteinfamilie stellt Rho neben Ras, Rab, Arf und Ran eine von fünf Subfamilien der kleinen G-Proteine dar (s. Abb. 3). Mehr als 100 dieser Guanosintriphosphat (GTP)-bindenden Proteine sind bereits klassifiziert worden und wurden aufgrund phylogenetischer Gemeinsamkeiten in die oben genannten Unterfamilien eingeteilt. Kleine G-Proteine regulieren diverse zelluläre Aktivitäten wie Zellproliferation (Ras), Vesikeltransport (Rab) und wie bereits erwähnt die Dynamik des Zytoskeletts (Rho), was unter anderem die Adhäsion, Migration, Polarität und die morphologische Form von Zellen betrifft (Heasman und Ridley 2008). Die Rho-GTPasen teilen sich nochmals in über 20 Unterformen auf, wovon RhoA, Rac1 und Cdc42 die am besten untersuchten Vertreter sind. Rac1 vermittelt durch Aktin-Polymerisierung die Ausbildung von Lamellipodien und Kräuselungen der Zellmembran (membrane ruffles), während Cdc42 eine Rolle in der Regulation der Zellpolarität und der Bildung von Filopodien spielt (Hall 2012). RhoA führt bei Aktivierung zur Ausbildung kontraktiler Aktomyosinbündel, was beispielsweise relevant für die Translokation von Zellen ist (Ridley und Hall 1992). In Anbetracht der beschriebenen Funktionen der Rho-Proteine liegt eine Beteiligung bei Krebserkrankungen nahe. Tatsächlich konnte von Sahai et al. gezeigt werden, dass RhoA in verschiedene Stufen der Tumorprogression, wie den Verlust der Zellpolarität, Intravasation oder die Vaskularisation von Tumoren involviert ist (Sahai und Marshall 2002). 
Einleitung

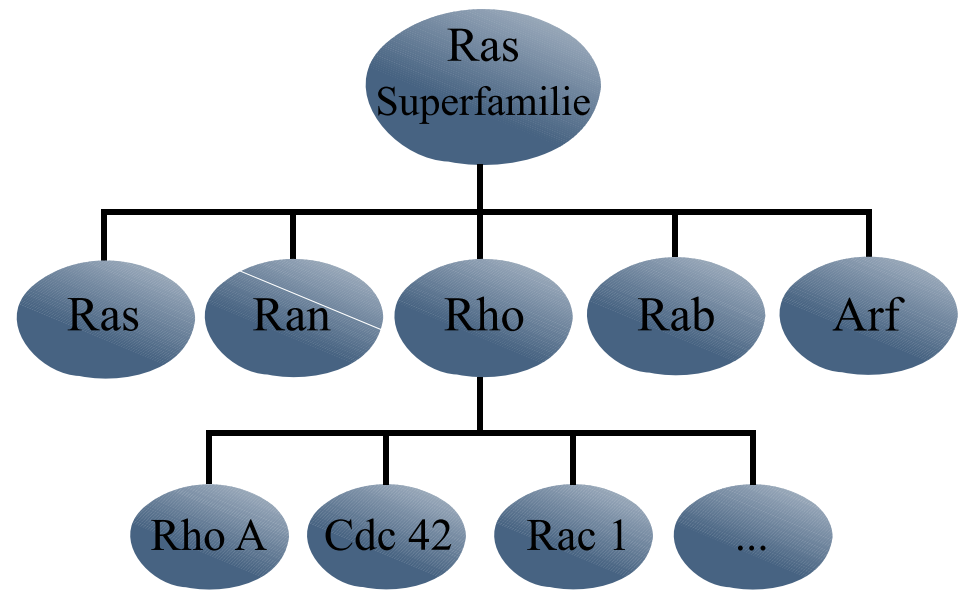

Abb. 3: Systematik der kleinen G-Proteine. Modifiziert nach Ridley, 2001. Die Ras-Superfamilie der kleinen GTPasen wird in Familien und Subfamilien unterteilt. Zu den fünf Hauptfamilien zählen Ras, Ran, Arf, Rab und Rho. RhoA ist eine kleine GTPase der Rho-Famile.

Die Bindung von Wachstumsfaktoren oder Zytokinen an Rezeptoren in der Plasmamembran moduliert die Aktivität Rho-regulierender Proteine. Somit übersetzen Rho-GTPasen extrazelluläre Veränderungen auf intrazelluläre Signalwege (Hall 1998; Vega und Ridley 2008). Rho-GTPasen verhalten sich wie molekulare Schalter, das heißt, sie wechseln zwischen einem aktiven Zustand (GTP-gebunden), in dem sie mit Effektorproteinen interagieren, und einem inaktiven Zustand (GDP-gebunden). Dieser Wechsel wird strikt von drei Proteingruppen reguliert (s. Abb. 4): GTP-Austausch-Faktoren (engl. guanine nucleotide exchange factors GEFs) bewirken eine Ablösung von gebundenem GDP. Dies erhöht die Wahrscheinlichkeit einer erneuten Bindung, jedoch diesmal des reichlich vorliegenden GTPs, was eine Aktivierung des kleinen G-Proteins zur Folge hat (Cerione und Zheng 1996). Die Gruppe der GTPaseaktivierenden Proteine (GAPs) bindet aktivierte Rho-GTPasen und katalysiert deren intrinsische GTPase-Aktivität, was zur Hydrolyse des gebundenen GTP zu GDP plus Phosphat führt und die Rho-GTPase inaktiviert (Ridley 2001). Die dritte Gruppe stellen die Guaninnukleotid-Dissoziations-Inhibitoren (GDIs) dar. Sie binden inaktivierte, GDPgebundene Rho-GTPasen und halten sie gelöst im Zytosol in ihrer inaktiven Form (Olofsson 1999). Um eine spezifische Regulation der zahlreichen Rho-GTPasen zu gewährleisten, ist eine hohe Zahl an GAPs, GEFs und GDIs nötig (Etienne-Manneville und Hall 2002). 


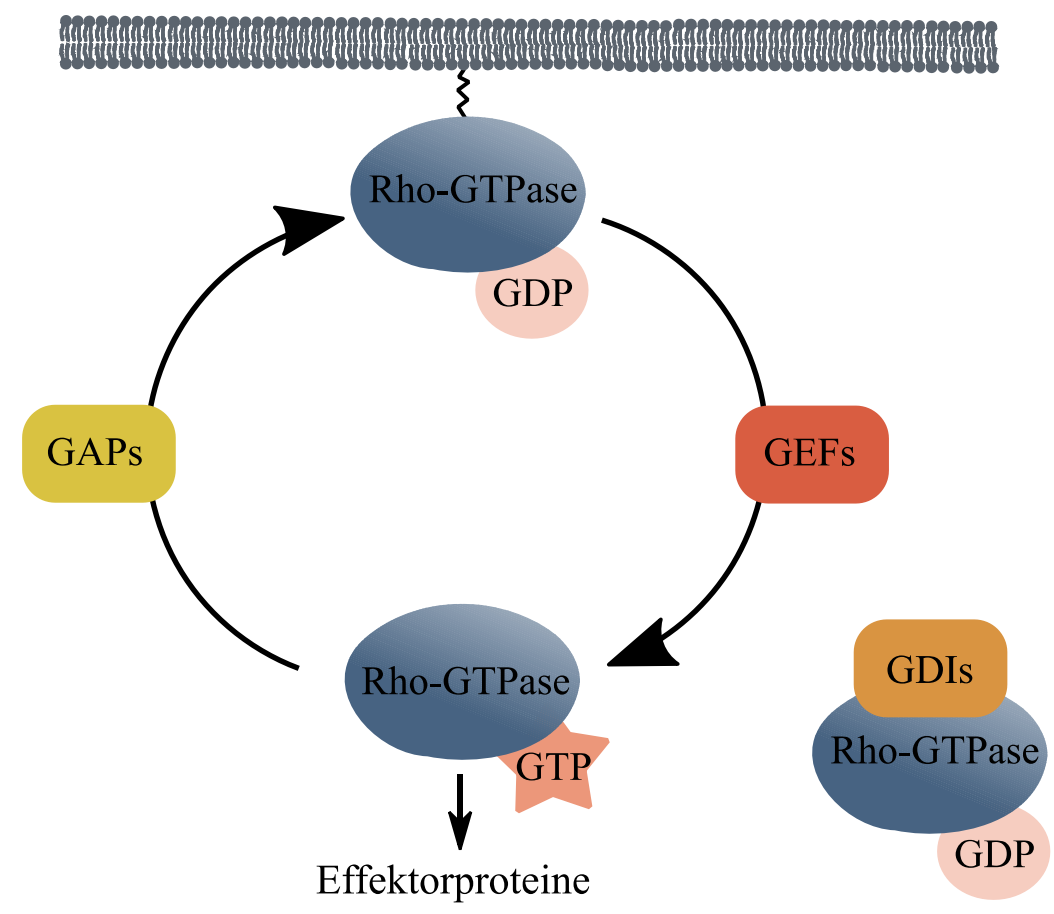

\begin{abstract}
Abb. 4: Regulation der Rho-GTPasen. Membranständige, inaktive, Rho-GTPasen binden GDP; GEFs katalysieren den Austausch von GDP zu GTP und damit die Aktivierung der Rho-GTPase. In ihrer aktiven Form beeinflussen die Rho-GTPasen verschiedene Effektorproteine. GAPs aktivieren die GTPase-Aktivität der RhoGTPase wodurch das gebundene GTP zu GDP hydrolysiert wird und wieder in der inaktiven Form vorliegt. GDIs halten GDP-tragende Rho-GTPasen in ihrer inaktiven Form im Zytosol gebunden. Modifiziert nach Tcherkezian und Lamarche-Vane, 2007 (Tcherkezian und Lamarche-Vane 2007).
\end{abstract}

\title{
1.6 Das Aktinzytoskelett in Hypoxie
}

Sauerstoffmangel bewirkt in Zellen sowohl morphologische als auch funktionelle Anpassungsmechanismen, die u. a. durch eine veränderte Dynamik des Aktinzytoskeletts zu erklären sind. Wie von Vogler et al. 2013 beschrieben, zeigten hypoxische L929-Fibroblasten eine Zunahme der Zellfläche und des Zellvolumens sowie eine gesteigerte Anzahl von Vinculin-positiven Fokalkontakten. Das sogenannte Spreading (Anhaften der Zelle am Untergrund) war beschleunigt und die Zellmigration verlangsamt. Außerdem wurde unter Hypoxie eine Umverteilung der zytoplasmatischen Aktinisoformen $\beta_{\text {cyto- }}$ und $\gamma_{\text {cyto-Aktin }}$ gefunden: In Normoxie überlappten die Isoformen größtenteils in der Zelle; unter Sauerstoffmangel kam es jedoch zu einer Segregation, wobei das $\beta_{\text {cyto-Aktin vor allem }}$

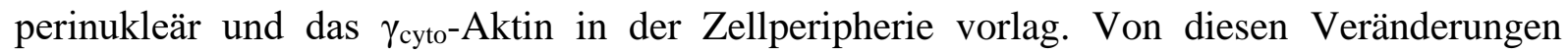
konnten die Zellflächenzunahme, die verlangsamte Zellmigration und die Umverteilung der Aktinisoformen als HIF-1 $\alpha$-abhängig identifiziert werden (Vogler et al. 2013). Sowohl die vorher beschriebene hypoxische Zunahme des Zellvolumens in anderen Zelltypen (Brillault et al. 2008; Rutkowsky et al. 2011) als auch eine Aktinumverteilung unter Hypoxie (Kayyali et al. 2002) sind stimmig mit diesen Resultaten. Gilkes et al. beschrieben ebenso eine erhöhte Anzahl von Fokalkontakten und die vermehrte Ausbildung von stress fibres in hypoxischen 
Einleitung

MDA-MB-231-Brustkrebszellen, beobachteten jedoch eine höhere Migrationsgeschwindigkeit als in normoxischen Zellen (Gilkes et al. 2014).

\subsubsection{Regulation des Aktinzytoskeletts in Hypoxie}

Der Einfluss von Hypoxie auf die in 1.5 beschriebene Regulation des Aktinzytoskeletts durch Rho-GTPasen kann beispielhaft anhand des Signalwegs des aktinbindenden Proteins Cofilin (Abb. 5) verdeutlicht werden.

Cofilin ist in dephosphoryliertem Zustand aktiv und bewirkt eine Depolymerisierung von Aktinfilamenten. Umgekehrt ist phosphoryliertes Cofilin inaktiv, was die Ausbildung von filamentösem Aktin begünstigt. Unter Hypoxie erfolgt über Aktivierung der Rho-GTPase RhoA sowie der Rho-assoziierten Kinase (ROCK - rho-associated, coiled-coil-forming protein kinase) die Aktivierung der LIM-Kinase (Maekawa et al. 1999). Diese vermittelt eine HIF-1 $\alpha$ abhängige Phophorylierung, also Deaktivierung von Cofilin, was den Aufbau von F-Aktin zur Folge hat (Vogler et al. 2013). Der Grad der Phosphorylierung entspricht dabei der Polymerisierungsaktivitiät von Cofilin und vice versa (Mizuno 2013). Das bedeutet, je mehr Hypoxie eine Zelle ausgesetzt ist, desto mehr filamentöses Aktin wird gebildet.

Eine Aktivierung von RhoA unter hypoxischen Bedingungen wurde sowohl für die in dieser Arbeit untersuchten L929-Fibroblasten als auch in zahlreichen weiteren Zellreihen beschrieben, jedoch zeigte sich kein einheitlicher Effekt (Zieseniss 2014). Sowohl Zelltyp als auch Versuchsaufbau scheinen die zelluläre Reaktion auf Hypoxie zu modulieren (Bailly et al. 2004). In Brustkrebszellen konnten Gilkes et al. RhoA und die Rho-assoziierte Kinase ROCK als direkte Zielgene von HIF-1 und HIF-2 identifizieren (Gilkes et al. 2014).

Die beschriebenen zellulären Vorgänge, die vermutlich nur einen Bruchteil der stattfindenden Prozesse widerspiegeln, weisen auf ein kompliziertes und vielseitiges Regulationssystem des Aktinzytoskeletts hin, bei dem Regelmäßigkeiten schwer abzuleiten sind. Es kann jedoch festgehalten werden, dass zahlreiche Zelllinien in Hypoxie vermehrt stress fibres ausbilden und sich Migrationsverhalten sowie die Zell-Zell- und Zell-EZM-Interaktionen ändern. Die Ausbildung kontraktiler Aktomyosinbündel (stress fibres) konnte sowohl in hypoxischen MDA-MB-231-Zellen als auch in porzinen glatten Muskelzellen der Pulmonalarterie (PASMCs) gefunden werden (Wang et al. 2001; Bailly et al. 2004; Gilkes et al. 2014). 
Einleitung

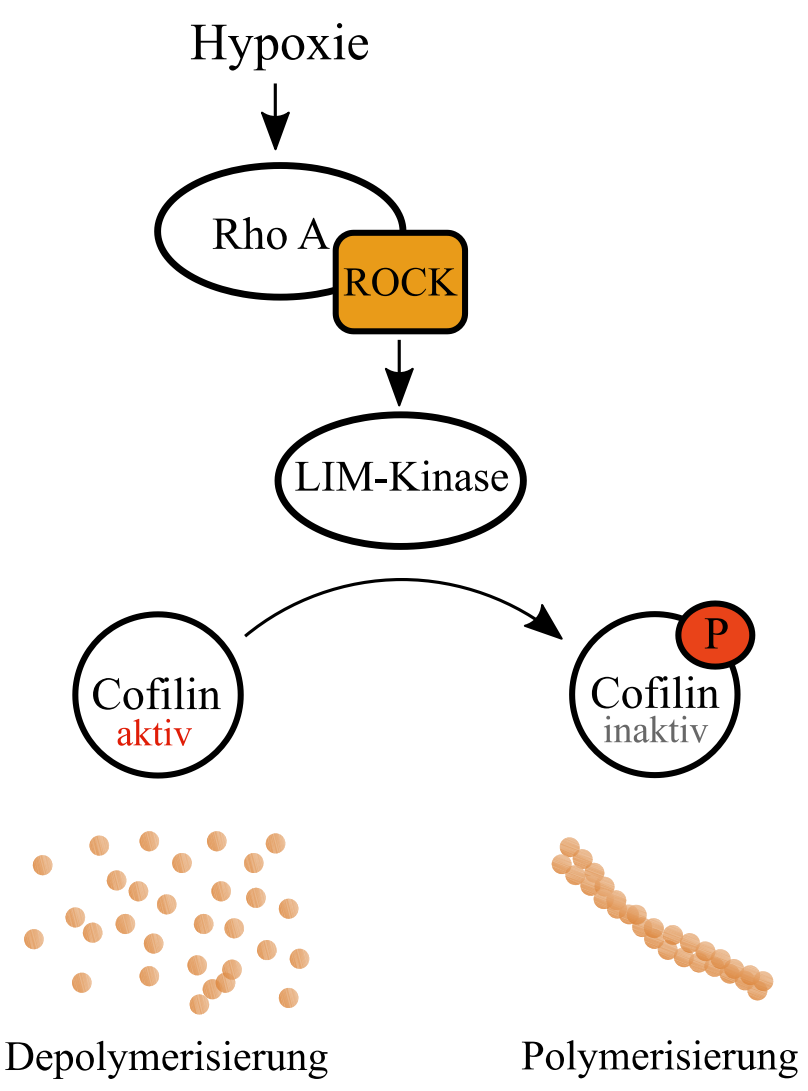

Abb. 5: RhoA vermittelt die Hypoxie-induzierte Inaktivierung von Cofilin. Die Rho-assoziierte Kinase (ROCK) vermittelt über die LIM-Kinase eine Phosphorylierung und damit die Inaktivierung des aktindepolymerisierenden Proteins Cofilin. Modifiziert nach Zieseniss, 2014.

\subsection{ArhGAP29}

In der Arbeitsgruppe von Frau Prof. Katschinski (Institut für Herz- und Kreislaufphysiologie, Georg-August-Universität Göttingen) wurde in einem Transkriptomscreen in Makrophagen eine hypoxische Regulation verschiedener GAP-, GEF- und GDI-Gene beobachtet. Ein Vertreter dieser Kandidatengene codiert für das Rho-GTPase aktivierende Protein 29 (ArhGAP29). Es induziert die GTPase-Reaktion von G-Proteinen und wirkt daher hemmend auf ihre Signalwirkung. ArhGAP29, das im Menschen auch als PARG1 (PTPL1-assoziiertes RhoGAP1) und als Homolog im Nematoden Caenorhabditis elegans als Spv-1 bekannt ist, wirkt hauptsächlich auf RhoA sowie dessen Homologe RhoB und RhoC, weniger auf Rac1 und Cdc42 (Reinhard et al. 2016). ArhGAP29 wird in zahlreichen Geweben der Hausmaus exprimiert, vor allem in Hoden, Lunge, subkutanem Fettgebewese, Ovarien, jedoch auch überdurchschnittlich im Herzgewebe, welches in dieser Arbeit anhand von kardialen L929Fibroblasten untersucht wurde (Saras et al. 1997).

Hinsichtlich der Regulation von ArhGAP29 konnten Post et al. in Experimenten an HUVECund HEK293T-Zellen zeigen, dass ArhGAP29 ein Effektorprotein des kleinen G-Proteins Rap1 


\section{Einleitung}

ist, welches das Zellspreading sowie die endotheliale Barrierefunktion reguliert (s. Abb. 6). In diesem Signalweg induziert Rap1 die Translokation des Ras-interacting protein1 (Rasip1) sowie des an Radil gebundenen ArhGAP29 an die Zellmembran. Die Proteine bilden einen multimeren Komplex und es kommt zur Aktivierung von ArhGAP29. Durch seine GAP-Aktivität inhibiert ArhGAP29 die GTPase RhoA und sorgt damit für eine verminderte Aktivierung von ROCK und ein geringeres Level von phosphorylierten leichten Myosinketten. In zuvor untersuchten A549-Epac1-Zellen konnte durch Post et al. eine verminderte Ausbildung von kontraktilen Aktomyosinbündeln beobachtet werden, die einerseits zu einem schnelleren Spreading der Zelle führt, andererseits die endotheliale Membranfunktion intakt hält, indem die Adhärensverbindungen durch geringere Zugkräfte weniger belastet werden (Post et al. 2013; Post et al. 2015).

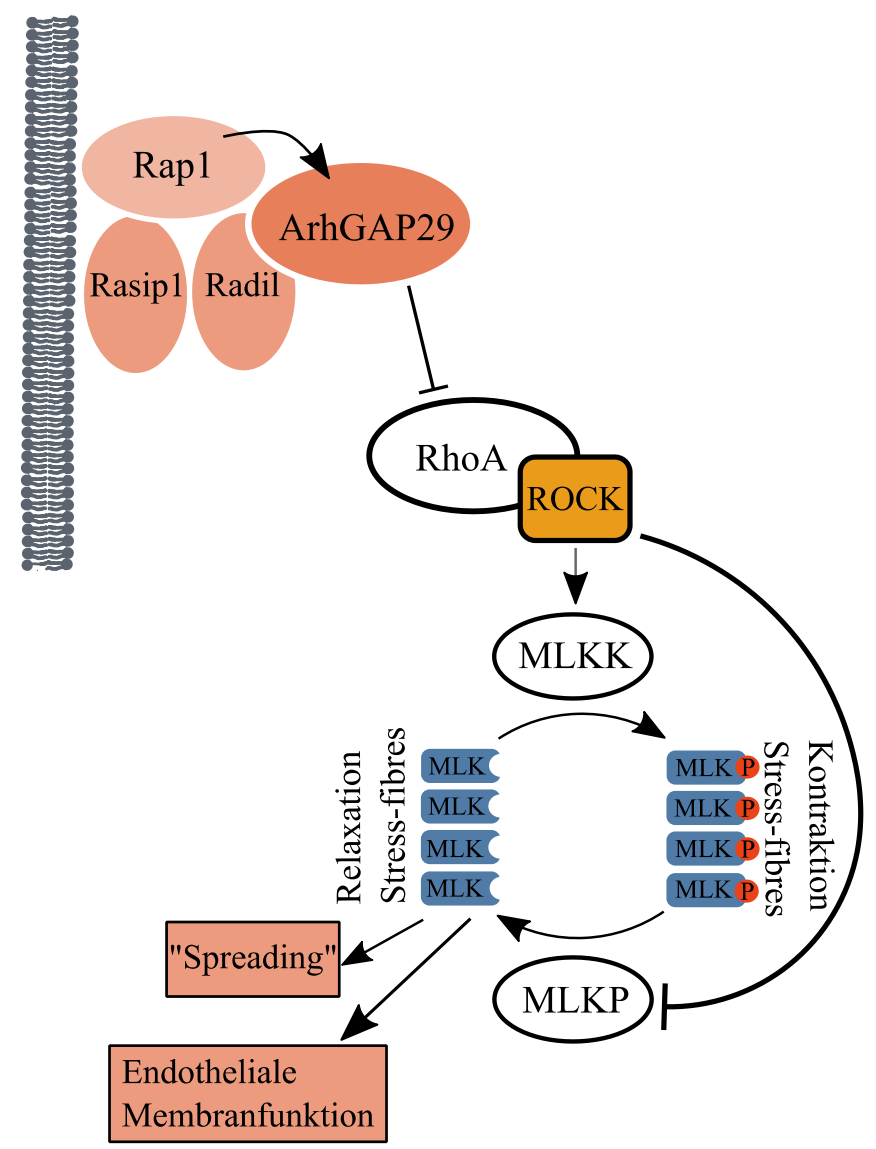

\footnotetext{
Abb. 6: ArhGAP29 als Effektorprotein von Rap1. Das kleine G-Protein Rap1 (ras-related protein 1) vermittelt eine Translokation zur Zellmembran von Rasip1, Radil und ArhGAP29, wo es ArhGAP29 in einem multimeren Komplex aktiviert. ArhGAP29 hemmt RhoA und induziert über eine verminderte Aktivität von ROCK eine verminderte Phosphorylierung der MLKs. Die daraus folgende Relaxation bewirkt eine verbesserte endotheliale Barrierefunktion und ein beschleunigtes Spreading der Zelle. Erklärung: MLKK: Myosin-Leichtketten-Kinase, MLKP: Myosin-Leichtketten-Phosphatase, P: Phosphatgruppe. Grafik modifiziert nach Post et al. 2013 und Post et al. 2015.
} 


\section{Einleitung}

Auch bei der Tubulogenese von Blutgefäßen spielt der Komplex Rasip/ArhGAP29 eine Rolle. In der Embryonalentwicklung von Mäuseembryos ist an Tag 8,5, also während der Vaskulogenese, das Protein ArhGAP29 in der Aorta dorsalis nachweisbar. Passend dazu sind Maus-Endothelzellen bei Knock-down von sowohl Rasip1 als auch ArhGAP29 nicht in der Lage ein Lumen zu bilden. Auf molekularer Ebene konnte festgestellt werden, dass zur Lumenbildung in Blutgefäßen die Inaktivierung von RhoA sowie die Aktivierung von Rap1 und Cdc42 durch Rasip1/ArhGAP29 notwendig sind (Xu et al. 2011). Daher sind Mäuse mit Knock-out des ArhGAP29-Gens nicht überlebensfähig; sie sterben noch während der Embryonalentwicklung an einem Plazentadefekt und zeigen darüber hinaus eine verengte Aorta dorsalis (Barry et al. 2016).

\subsection{Zielsetzung der Arbeit}

Mit dieser Arbeit soll das Verständnis erweitert werden, wie sich eine hypoxische Umgebung auf die Dynamik des Aktinzytoskeletts einer Zelle auswirkt. Da eine Vielzahl von Erkrankungen des Menschen mit Hypoxie einhergeht, kann ein verbessertes Wissen von zellulären Reaktionen auf Sauerstoffmangel in Zukunft neue Therapiemöglichkeiten für diese Krankheiten bedeuten. Durch die Experimente an L929-Fibroblasten und C2C12-Myoblasten soll insbesondere die hypoxische Regulation von RhoA und dessen Auswirkungen auf das Aktinzytoskelett untersucht werden.

In hypoxischen Zellen sind deutliche morphologische Veränderungen zu beobachten, eine genaue Analyse der molekularen Mechanismen ist jedoch komplex und scheint noch weit entfernt. In vorherigen Veröffentlichungen zeigten Rho-GTPasen, die das Aktinzytoskelett regulieren, veränderte Expressions- und Aktivitätslevel unter Hypoxie.

Wie genau die Rho-Aktivität jedoch unter hypoxischen Bedingungen reguliert wird und wie die Regulatoren der Rho-GTPasen, die GEFs, GAPs und GDIs die hypoxische Rho-Aktivität beeinflussen, ist bisher nicht geklärt und soll in der vorliegenden Arbeit untersucht werden. Insbesondere wird hierbei das Augenmerk auf das Rho-GTPase-aktivierende Protein 29 (ArhGAP29) gelegt, welches als direkter Regulator von RhoA und einer hypoxischen Induktion eine Schnittstelle zwischen der Dynamik des Aktinzytoskeletts und der Sauerstoffhomöostase von Zellen sein könnte. 


\section{Material und Methoden}

\subsection{Material}

\subsubsection{Chemikalien \& Reagenzien}

Chemikalien wurden, wenn nicht anders angegeben, von den Firmen Sigma Aldrich, Hamburg, Deutschland; Applichem, Darmstadt, Deutschland und Carl Roth GmbH \& Co, Karlsruhe, Deutschland erworben

Name

Bactotrypton

Bactoyeast

Bradford-Reagenz

DMEM

FCS

LentiX Concentrator

Lipofectamine 2000

OptiMEM

Pen/Strep

Phalloidin-FITC

Page Ruler Prestained ${ }^{\mathrm{TM}}$

Protease-Inhibitor

(cOmplete Cocktail Tablets)

Puromycin

SDS

Trypsin

TRIZOL®

\section{Herkunft}

BD, Franklin Lakes, USA

BD, Franklin Lakes, USA

Bio-Rad Laboratories, Hercules, USA

$\operatorname{Pan}^{\mathrm{TM}}$ Biotech GmbH, Aidenbach, Deutschland

$\operatorname{Pan}^{\mathrm{TM}}$ Biotech GmbH, Aidenbach, Deutschland

Clontech Laboratories Inc., Mountain View, USA

Invitrogen Life Technologies, Carlsbad, USA

Gibco Life Technologies, Darmstadt, Deutschland

$\operatorname{Pan}^{\mathrm{TM}}$ Biotech $\mathrm{GmbH}$, Aidenbach, Deutschland

Alexa Life Technologies, Carlsbad, USA

Thermo Scientific, Waltham, USA

Roche, Mannheim, Deutschland

Gibco Life Technologies, Carlsbad, USA

Thermo Scientific, Waltham, USA

$\operatorname{Pan}^{\mathrm{TM}}$ Biotech GmbH, Aidenbach, Deutschland

Invitrogen Life Technologies, Darmstadt, Deutschland 
Material und Methoden

\subsubsection{Puffer \& Medien}

\section{Name}

Ammoniumacetatlösung

Cumarsäure

DMEM

DYT-Medium

Entwicklungslösung für

Western Blot

Laemmli-Puffer (5x)

Laufpuffer (5x)

\section{Zusammensetzung}

2,25 M Ammoniumacetat in $\mathrm{H}_{2} \mathrm{O}$

90 mM Cumarsäure

$14,8 \mathrm{~g} / \mathrm{ml}$ DMSO

4,5 g/l Glucose

$584 \mathrm{mg} / \mathrm{l} \mathrm{Glutamin}$

$110 \mathrm{mg} / \mathrm{l}$ Pyruvat

$3,7 \mathrm{~g} / \mathrm{l} \mathrm{NaHCO}$

16 g Bactotrypton (Casein Hydrolysat Pepton Nr.140)

$10 \mathrm{~g}$ Bacto Yeast (Bacto Yeast Extrakt)

$5 \mathrm{~g} \mathrm{NaCl}$

auf $1000 \mathrm{ml}$ Aqua dest. auffüllen und autoklavieren

0,1 M Tris/HCl pH 8,5

$1 \% \mathrm{H}_{2} \mathrm{O}_{2}$

1,25 mM Luminol

0,225 mM Cumarsäure

$190 \mathrm{mM}$ SDS

55 mM EDTA

$55 \mathrm{mM} \mathrm{Na}_{2} \mathrm{HPO}_{4}$

$25 \%$ Glycin

$20 \% \beta$-Mercaptoethanol

$0,1 \%$ Bromphenolblau

25 mM Tris-HCl, pH 8,2

192 mM Glycin

$20 \%(\mathrm{v} / \mathrm{v})$ Methanol

$0,1 \%(w / v)$ SDS 
Material und Methoden

LB-Agar

40 g Agarpulver

auf $1000 \mathrm{ml}$ Aqua dest.

LB-Medium

$5 \mathrm{~g} / \mathrm{l} \mathrm{Hefeextrakt}$

$10 \mathrm{~g} / 1$ Trypton

$10 \mathrm{~g} / \mathrm{l} \mathrm{NaCl}$

Zell-Lyse-Puffer

10 mM Tris- $\mathrm{HCl}, \mathrm{pH} 8,0$

1 mM EDTA

$400 \mathrm{mM} \mathrm{NaCl}$

$0,1 \%$ Triton $\mathrm{X}-100$

$10 \%$ Protease Inhibitor

M9-Puffer

$3 \mathrm{~g} \mathrm{KH}_{2} \mathrm{PO}_{4}$

$6 \mathrm{~g} \mathrm{Na}_{2} \mathrm{HPO}_{4}$

$5 \mathrm{~g} \mathrm{NaCl}$

$1 \mathrm{ml} \mathrm{MgSO} 4$-Lösung

NGM-Agar

$6 \mathrm{~g} \mathrm{NaCl}$

29 g Agar-Agar

$10 \mathrm{~g}$ fettes Pepton

$2 \mathrm{ml}$ Cholesterin-Lösung

$1900 \mathrm{ml} \mathrm{H}_{2} \mathrm{O}$ dest.

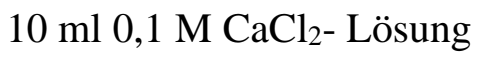

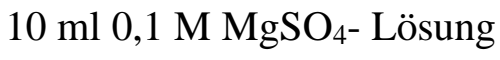

$50 \mathrm{ml} 1 \mathrm{M}$ Kaliumphosphatpuffer $(\mathrm{pH}=6)$

10 ml Nystatinlösung

$10 \mathrm{ml}$ 20\%ige Sucroselösung

Nystatinlösung

4 g Nystatin

$200 \mathrm{ml}$ Ethanol

200 ml Ammoniumacetatlösung 
Material und Methoden

PBS $(\mathrm{pH}=7,4)$

$137 \mathrm{mM} \mathrm{NaCl}$

2,7 $\mathrm{mM} \mathrm{KCl}$

$10,2 \mathrm{mM} \mathrm{Na}_{2} \mathrm{HPO}_{4} \times 2 \mathrm{H}_{2} \mathrm{O}$

$1,8 \mathrm{mM} \mathrm{KH}_{2} \mathrm{PO}_{4}$

Reaktionspuffer (5x) für

250 mM Tris-HCl

First Strand cDNA

$250 \mathrm{mM} \mathrm{KCl}$

Synthese Kit

$20 \mathrm{mM} \mathrm{MgCl}_{2}$

$50 \mathrm{mM}$ DTT

Transferpuffer $(\mathrm{pH}=8) \quad 50 \mathrm{mM}$ Tris

$384 \mathrm{mM}$ Glycin

20\% Methanol

\subsubsection{Kits}

\section{Name}

First Strand cDNA

Synthese Kit

Sensi Mix SYBR Low

Rox Kit für qRT-PCR

QIAprep Spin miniprep Kit QIAGEN, Hilden, Deutschland

LentiX Concentrator Kit Clontech Laboratories Inc., Mountain View, USA

ViralPower lentiviral

Life Technologies, Paisley, UK

\section{Herkunft}

Thermo Scientific, Ottawa, Kanada

Bioline, Luckenwalde, Deutschland

Expression system 
Material und Methoden

\subsubsection{Geräte und Materialien:}

Name

Deckgläschen

Elektro-Blotter

Gelelektrophoresekammer

Hypoxie-Box „InvivO $2400 “$

Kühlzentrifuge

(Centrifuge 5415R)

LAS-3000

Microplate Reader

Model 680

Mikroskop

MxPro-Mx3005P Cycler

Reaktionsgefäße

$(0,2 ; 0,5 ; 1,5 ; 2 \mathrm{ml})$

PCR-Cycler Primus 96

Reaktionsgefäße

(15 und 50ml)

Röntgenfilme (grau)

Röntgenfilme (blau)

Schüttelgerät

(Infors HT minitron)

Spektrophotometer

Sterilbank „HERAsafe”

Thermocycler

Tischzentrifuge

Elektroblotter

Zell-Inkubator

Zellkulturschalen

\section{Herkunft}

Carl ROTH GmbH \& Co, Karlsruhe, Deutschland

PeqLab Biotechnology GmbH, Erlangen, Deutschland

Carl ROTH GmbH \& Co, Karlsruhe, Deutschland

Ruskinn Technology Ltd., Pencoed, Großbritannien

Eppendorf, Hamburg, Deutschland

Fujifilm, Düsseldorf, Deutschland

Bio-Rad Laboratories, Hercules, USA

Axio Observer D1, Carl Zeiss, Göttingen, Deutschland

Stratagene, La Jolla, USA

Sarstedt, Nümbrecht, Deutschland

PeqLab Biotechnology GmbH, Erlangen, Deutschland

Greiner Bio-One, Kremsmünster, Österreich

GE Healthcare Ltd, Little Chalfont, UK

Santa Cruz Biotechnology Inc., Heidelberg, Deutschland

Infors HAT, Bottmingen, Schweiz

Bio-Rad Laboratories, Hercules, USA

Thermo Scientific, Ottawa, Kanada

PeqLab Biotechnology GmbH, Erlangen, Deutschland

Thermo Scientific, Ottawa, Kanada

PeqLab Biotechnology GmbH, Erlangen, Deutschland

Binder, Tuttlingen, Deutschland

Sarstedt, Nümbrecht, Deutschland 


\subsection{Methoden}

\subsubsection{Zellen}

\subsubsection{Zelllinien}

Die Auswirkungen von Hypoxie auf das Aktinzytoskelett und die Expression von GEFs und GAPs in Zellen wurde an L929-Fibrosarkom-Fibroblasten sowie an C2C12-Myoblasten untersucht; beides sind immortalisierte Mauszelllinien. Weiterhin wurde ein L929-Zellklon mit Knock-down des HIF-1 $\alpha$-Gens (shHIF-1 $\alpha$ ) sowie eine L929-Sh-Kontrollzelllinie verwendet (Sh-Kontrolle). Im Rahmen dieser Arbeit wurden zusätzlich zwei L929-Zellklone mit Knockdown des ArhGAP29-Gens (Kd1 und Kd2) hergestellt. Diese wurden durch lentivirale Transduktion verschiedener short-hairpin-RNA-Vektoren gewonnen. In shHIF-1 $\alpha$, Kd1 und Kd2 führte die shRNA mittels RNA-Interferenz zu einer stabilen Stilllegung des HIF-1 $\alpha$ bzw. ArhGAP29-Gens, wohingegen in der Sh-Kontrolle durch die verwendete non-targeting-shRNA kein Effekt auf die Genexpression erfolgte (Vogler et al. 2013).

\subsubsection{Kultivierung von Zellen}

Die Kultivierung der L929-Fibroblasten und C2C12-Myoblasten erfolgte in Dulbecco's modified Eagle's medium (DMEM). Dem Medium wurden 10\% FCS sowie 1\% Penicillin (100 U/ml) und Streptomycin $(100 \mu \mathrm{g} / \mathrm{ml})$ zugegeben. Zur Selektion der mit dem sh-Plasmidtransduzierten Zellreihen (Sh-Kontrolle, shHIF-1 $\alpha$ sowie Kd1 und Kd2) wurde Puromycin in einer Konzentration von $20 \mu \mathrm{g} / \mathrm{ml}$ Medium eingesetzt. Zum Passagieren wurde Trypsin mit EDTA $(0,5 \mathrm{M}, 2 \mu \mathrm{g} / \mathrm{ml})$ benutzt.

Die Zellen wurden im Zellkultur-Brutschrank bei $37{ }^{\circ} \mathrm{C}, 20 \% \mathrm{O}_{2}$ und $5 \% \mathrm{CO}_{2}$ inkubiert. Um Zellen hypoxischen Bedingungen auszusetzen wurden sie in einer Hypoxie-Box kultiviert, in $\operatorname{der} 37^{\circ} \mathrm{C}, 1 \% \mathrm{O}_{2}$ und $5 \% \mathrm{CO}_{2}$ herrschten.

\subsubsection{Virologische Methoden}

Um die Expression des ArhGAP29-Gens in L929-Zellen zu verringern (Knock-down) wurde spezifische short-hairpin-Sequenz mithilfe von lentiviraler Transduktion in das Genom der Zielzellen eingebaut. Dadurch bildet der Zellkern durch Transkription selbstständig shRNA, die durch das Protein Dicer zu small-interfering-(si-)RNA verändert wird. Die siRNA setzt sich zusammen mit weiteren Proteinen zum sogenannten RNA-induced Silencing Complex (RISC) zusammen, der anhand der einsträngigen siRNA komplementäre mRNA bindet und degradiert. Abhängig vom Ausgangsvektor kann so eine posttranskriptionale Gen-Stilllegung erreicht werden, die mRNA-Fragmente eines bestimmten Gens zwischen Transkription und Translation 
degradiert. Für diese Arbeit wurden dazu die in Tab. 1 aufgeführten Plasmidvektoren verwendet. Im weiteren Text werden die mit Vektor TRCN0000361989 transduzierten Zellen mit Knock-down des ArhGAP29-Gens Knock-down1 (Kd1) genannt werden, die ArhGAP29knock-down-Zellen aus dem Vektor TRCN0000023926 heißen Knock-down2 (Kd2).

Tabelle 1: Verwendete Plasmidvektoren für den ArhGAP29-knock-down

\begin{tabular}{|l|l|l|l|}
\hline Name & Klon-ID & Sequenz & Firma \\
\hline $\begin{array}{l}\text { TRCN000 } \\
0361989\end{array}$ & $\begin{array}{l}\text { NM_172525.2 } \\
-1901 \text { s21c1 }\end{array}$ & $\begin{array}{l}\text { CCGGCCATTGAAACATTGGCATTTAC } \\
\text { TCGAGTAAATGCCAATGTTTCAATGG } \\
\text { TTTTT }\end{array}$ & $\begin{array}{l}\text { Sigma-Aldrich, } \\
\text { St. Louis, USA }\end{array}$ \\
\hline $\begin{array}{l}\text { TRCN000 } \\
0023926\end{array}$ & $\begin{array}{l}\text { NM_172525.1 } \\
-1819 \mathrm{~s} 1 \mathrm{c} 1\end{array}$ & $\begin{array}{l}\text { CCGGCCAGGAGACTTTCATCGGAAAC } \\
\text { TCGAGTTTCCGATGAAAGTCTCCTGG } \\
\text { TTTTT }\end{array}$ & $\begin{array}{l}\text { Sigma-Aldrich, } \\
\text { St. Louis, USA }\end{array}$ \\
\hline
\end{tabular}

\subsection{Plasmidpräparation}

Für die Plasmidpräparation wurden zunächst Einzelkolonien der plasmidtragenden E. coliBakterien von Agarplatten in $5 \mathrm{ml}$ LB-Medium (+5 $\mu \mathrm{l}$ einer $286 \mathrm{mM}$ Ampicillinlösung) gegeben. Diese Vorkultur wurde für $8 \mathrm{~h}$ bei $37^{\circ} \mathrm{C}$ in einem Schüttler inkubiert. Davon wurden $500 \mu \mathrm{l}$ in $100 \mathrm{ml}$ LB-Medium (+100 $\mu \mathrm{l} 286 \mathrm{mM}$ Ampicillin) überführt und die Proben erneut über Nacht geschüttelt.

Die folgende Präparation erfolgte nach Handbuch des QIAGEN Spin mini Prep Kit.

\subsection{Herstellung von Lentiviren}

Für die Herstellung der Lentiviren wurde das lentivirale ViralPower Expressionssystem (Life Technologies, Paisley, UK) verwendet.

Zuerst wurden HEK293T-Zellen mit einer Zelldichte von $7 \times 10^{6}$ Zellen in $15 \mathrm{ml}$ DMEM (+10\% FCS, kein Penicillin und Streptomycin) ausgesät. Am Folgetag wurde das Medium gegen $5 \mathrm{ml}$ OptiMEM (+10\% FCS) ausgetauscht. In einem Röhrchen wurden die Packagingplasmide (4,2 $\mu \mathrm{g} \quad \mathrm{pLP} 1,2 \mu \mathrm{g} \quad \mathrm{pLP} 2, \quad 2,8 \mu \mathrm{g}$ pLP-VSVG) sowie $3 \mu \mathrm{g}$ des Expressionsvektors gemischt und auf 1,5 ml mit OptiMEM (ohne FCS) aufgefüllt. In ein weiteres Röhrchen wurden $36 \mu$ Lipofectamine 2000 gegeben und ebenfalls mit OptiMEM auf 1,5 ml aufgefüllt. Im Falle der Lipofektamin-vermittelten Transfektion bilden die Lipide im Lipofektamin Liposomen, die das zu transfizierende Genmaterial binden. Dadurch wird die Aufahme in die Zelle durch die lipophile Zellmembran hindurch ermöglicht. Nach 5 min Inkubationszeit bei Raumtemperatur wurde der Inhalt beider Röhrchen gemischt und wiederum für 20 min inkubiert. Das Gemisch wurde danach tropfenweise auf die ausgesäten Zellen 
gegeben. Am dritten Tag folgte ein Mediumwechsel mit DMEM (+10\% FCS, kein Penicillin und Streptomycin).

Die erste Ernte und Aufreinigung der Viren erfolgte am vierten Tag. Der Überstand der HEK293T-Zellen wurde in ein 50ml Röhrchen geerntet und für $15 \mathrm{~min}$ bei $3000 \mathrm{rpm}$ und $4{ }^{\circ} \mathrm{C}$ zentrifugiert, der Überstand wurde erneut abgenommen und für je 3 Teile Virusüberstand wurde 1 Teil LentiX Concentrator zum Aufreinigen zugegeben. Nach einer Inkubationszeit von 45 min bei $4{ }^{\circ} \mathrm{C}$ und einem 45 minütigen Zentrifugationsschritt bei $1500 \mathrm{rpm}$ und $4{ }^{\circ} \mathrm{C}$ wurde der Überstand abgesaugt und verworfen. Das Pellet wurde in $2 \mathrm{ml}$ Vollmedium (10\% FCS, $1 \%$ Penicillin und Streptomycin) aufgenommen und zu $2 \times 1 \mathrm{ml}$ Proben bei $-80{ }^{\circ} \mathrm{C}$ eingefroren. Am Folgetag konnten die durch die Zellen produzierten Viren ein zweites Mal auf dieselbe Weise aufgereinigt werden.

\subsection{Transduktion der Zielzellen}

Zur Transduktion wurden am ersten Tag L929-Zellen in $2 \mathrm{ml}$ Vollmedium in die Vertiefungen einer 6 Well-Platte bei einer Konzentration von 1 x 10 $10^{5}$ Zellen/ml ausplattiert. An Tag 2 erfolgte die Transduktion der Zellen bei 50\%iger Konfluenz. Es wurde $1 \mathrm{ml}$ der jeweiligen Virusüberstände mit den TRCN0000361989 bzw. TRCN0000023926 Lentiviren sowie mit $1 \mathrm{ml}$ Vollmedium und $16 \mu \mathrm{l}$ Polybrene in jedes Well auf die Zielzellen gegeben. In ein KontrollWell wurde anstatt $1 \mathrm{ml}$ Virusüberstand $1 \mathrm{ml}$ normales Vollmedium gegeben. Polybrene ist ein kationisches Polymer, das die Infektionsrate der Zellen mit dem Lentivirus durch Neutralisation von Ladungsabstoßung erhöht. Am dritten Tag wurde 3x mit Vollmedium gewaschen. Danach wurden die Zellen in größere Kulturschalen (Durchmesser: $6 \mathrm{~cm}$ ) transferiert und mit $2 \mu \mathrm{ldes}$ Selektionsantibiotikums Puromycin/ml Medium versehen.

Die Knock-downs konnten mittels qPCR (siehe 2.2.2.10) und Western Blot (siehe 2.2.2.7) bestätigt werden.

\subsubsection{Fluoreszenzfärbung}

Um das Aktinfilamentgerüst und die Morphologie von hypoxisch und normoxisch gehaltenen L929-Zellen vergleichen zu können, wurden diese mit FITC- markiertem Phalloidin zur Sichtbarmachung der Aktinfilamente inkubiert. Die DNA wurde mit Hoechst angefärbt.

Zur Fluoreszenzfärbung der Zellen wurden 0,3 x 10 $0^{5}$ Zellen/ml auf 20 x 20 mm Deckgläschen in $4 \mathrm{~cm}$ Zellkulturschalen ausgesät. Nach einer Inkubationszeit von $24 \mathrm{~h}$ bei $20 \% \mathrm{O}_{2}$ wurden die Zellen für weitere $24 \mathrm{~h}$ unter normoxischen $\left(20 \% \mathrm{O}_{2}\right)$ bzw. hypoxischen Bedingungen $\left(1 \% \mathrm{O}_{2}\right)$ kultiviert. 
Die Deckgläschen wurden dreimal mit PBS gewaschen und anschließend für 15 min in vierprozentigem PFA in PBS fixiert. Nach dreimaligem Waschen mit PBS folgte für 20 min die Permeabilisierung der Zellen mittels 0,2\% Triton X in PBS. Erneut wurde dreimal mit PBS gewaschen und die Zugabe von 1\% BSA in PBS erfolgte zur Reduzierung des Hintergrundes. Anschließend wurde das mit dem fluoreszierenden Farbstoff FITC markierte Phalloidin in einer Verdünnung von 1:400 für 60 min auf die Zellen gegeben. Ungebundenes Phalloidin wurde durch dreimaliges Waschen mit PBS entfernt. Anschließend wurde zur Färbung der DNA im Zellkern 1:500 verdünntes Hoechst für etwa 5 min zugegeben. Mit einem Tropfen Mowiol wurden die Zellen auf den Deckgläschen eingedeckelt und konnten am Fluoreszenzmikroskop (Axio Observer D1, Carl Zeiss, Göttingen, Deutschland) betrachtet werden. Zellgrößen wurden mit ImageJ-Software bestimmt.

\subsubsection{PHD-Inhibierung durch DMOG}

DMOG inhibiert unter normoxischen Bedingungen die enzymatische Aktivität der PHDs (s. 1.3) und stabilisiert somit HIF-1 $\alpha$. Um diesen Effekt in Zellkultur zu untersuchen, wurden beide zu untersuchenden Zellgruppen für $48 \mathrm{~h}$ in Normoxie inkubiert, jedoch wurde nach $24 \mathrm{~h}$ einer Gruppe $1 \mathrm{mM}$ DMOG zugegeben. Mittels qRT-PCR und Western Blot konnte die HIF$1 \alpha$-Stabilisierung auf RNA- und Proteinebene bestätigt werden.

\subsubsection{Proteinextraktion und -konzentrationsbestimmung}

Um hypoxische Veränderungen auf Proteinebene in Zellen beurteilen zu können, wurden die $\mathrm{zu}$ untersuchenden Zelllinien zuerst in einer Konzentration von 0,3 bzw. 1 x $10^{5}$ Zellen/ml ausgesät und für die ersten $24 \mathrm{~h}$ der Inkubation unter normoxischen Bedingungen $\left(20 \% \mathrm{O}_{2}\right)$ kultiviert. Danach wurde eine Hälfte der Zellen weiterhin bei Normoxie belassen, während die andere Hälfte in der Hypoxie-Werkbank hypoxischen Bedingungen $\left(1 \% \mathrm{O}_{2}\right)$ ausgesetzt und dort für 24 weitere Stunden inkubiert wurde.

Zur Gewinnung der Proteinextrakte aus den Zellen wurde das Medium abgekippt, zweimal mit kaltem PBS gewaschen und $100 \mu$ Lysepuffer $/ 6 \mathrm{~cm}$ Zellkulturschale zugegeben. Der Lysepuffer dient dem Zellaufschluss; er enthält 10\% Proteinaseinhibitor um den Proteinabbau zu verhindern. Die lysierten Zellen wurden abgeschabt und das Lysat für 12 min bei $13.200 \mathrm{rpm}$ und $4{ }^{\circ} \mathrm{C}$ zentrifugiert. Der Überstand konnte bei $-80{ }^{\circ} \mathrm{C}$ gelagert, oder weiterverarbeitet werden, das Pellet wurde verworfen.

Die Bestimmung der Proteinkonzentration erfolgte photometrisch nach der Bradford-Methode (Bradford 1976). Hierbei wurde ein spezielles Bradford-Reagenz (1:5 verdünnt) genutzt, das 
durch den enthaltenen Farbstoff Coomassie brilliant blue G-250 bei Proteinbindung durch Farbumschlag die Proteinmenge in einer Probe anzeigt.

Auf eine 96-well Platte wurden zuerst 0-8 $\mu$ BSA (0,5 mg/ml) pipettiert, die als Standardkurve dienten. Daneben wurde jeweils $1 \mu \mathrm{l}$ der zu messenden Proteinprobe aufgetragen. In die Vertiefungen wurde dann $200 \mu \mathrm{l}$ Bradford-Reagenz gegeben und mit dem Microplate Reader Model 680 (Bio-Rad) auf einer Wellenlänge von $595 \mathrm{~nm}$ die Absorption gemessen. So konnte anhand der Standardkurve die Proteinkonzentration in den Proben ermittelt werden.

\subsubsection{SDS-PAGE und Western Blot}

In der SDS-PAGE werden die Proteine ihrer Molekülmasse nach aufgetrennt. Jeder Probe wurde 1/5 des Probenvolumens (ca. 10-20 $\mu \mathrm{l}$ ) 5x Laemmli-Puffer zugegeben. Diese Proben wurden ebenso wie ein Größenmarker (PageRuler Prestained) auf ein Polyacrylamidgel (615\%) aufgetragen. Für die Detektion von ArhGAP29 wurden $200 \mu$ g Protein aufgetragen, für HIF-1 $\alpha 100 \mu \mathrm{g}$ Protein. Am Netzgerät wurde für die Elektrophorese eines Gels eine Stromstärke von 45 mA, eine Spannung von $300 \mathrm{~V}$ und eine Leistung von $100 \mathrm{~W}$ für ca. drei Stunden angelegt.

Nach erfolgter Gelelektrophorese hatten sich die Proteine ihrer Molekülmasse nach im Gel aufgetrennt. Das Gel wurde anschließend im Semi-Dry Blotting Verfahren zwischen transferpuffergetränkte Filterpapiere auf eine Nitrozellulosemembran in die Blotapparatur gelegt. Ein zum Gel senkrecht angelegtes Spannungsfeld übertrug die Proteine von dem Gel auf die Membran. Nach einer Stunde bei $2 \mathrm{~mA} / \mathrm{cm}^{2}$, $30 \mathrm{~V}$ und $100 \mathrm{~W}$ war der Proteintransfer abgeschlossen und die Membran konnte entnommen und mit Ponceau S angefärbt werden. Die reversible Ponceau S-Färbung dient als Transferkontrolle.

Im Folgenden wurde die Membran mit einem Gemisch aus 5\% Magermilchpulver in PBS für eine Stunde blockiert. Danach wurde der primäre Antikörper, verdünnt in ebenfalls PBS und 5\% Magermilchpulver, zugegeben und bei $4 \mathrm{C}^{\circ}$ über Nacht inkubiert. Anschließend wurde die Membran 3 x 10 min mit PBS gewaschen um überschüssige Antikörper von unspezifischen Bindungsstellen zu entfernen. Ein mit Horseradish peroxidase (HRP) gekoppelter sekundärer Antikörper wurde passend zur Quelle des primären Antikörpers ebenfalls in 5 prozentiger PBSMilch für eine Stunde auf die Membran gegeben. Dieser Schritt diente der spezifischen Bindung des sekundären an den primären Antikörper und war damit entscheidend für die Sichtbarmachung der Proteinbanden (zur Übersicht der benutzten Antikörper s. Tabelle 2). Es folgten drei weitere Waschschritte mit PBS, um unspezifisch gebundene Antikörper abzulösen. 
Zum Entwickeln wurde die Membran für eine Minute lang in eine $\mathrm{H}_{2} \mathrm{O}_{2-}$, luminol- und cumarsäurehaltige Entwicklungslösung getaucht. Das entstehende Chemilumineszenz-Signal zwischen der HRP am sekundärem Antikörper und dem in der Entwicklungslösung enthaltenen Luminol wurde mit einer LAS-3000-Kamera festgehalten. Falls das Signal zu schwach war, um mittels Kamera detektiert zu werden, wurde ein photoempfindlicher Chemilumineszenzfilm aufgelegt.

Tabelle 2: Übersicht der benutzten primären und sekundären Antikörper

\begin{tabular}{|l|l|l|l|l|l|}
\hline Name & Quelle & Verdünnung & Firma & Best.Nr. & Lagertemp. \\
\hline Primäre Antikörper & \multicolumn{5}{|l|}{} \\
\hline Anti-ARHGAP29 & $\begin{array}{l}\text { Hase } \\
\text { polyklonal }\end{array}$ & $1: 2500$ & Novus & $\begin{array}{l}\text { NBP1- } \\
05989\end{array}$ & $4{ }^{\circ} \mathrm{C}$ \\
\hline Anti-HIF-1 $\alpha$ (mouse) & $\begin{array}{l}\text { Kaninchen } \\
\text { polyklonal }\end{array}$ & $\begin{array}{l}1: 500- \\
1: 2000\end{array}$ & Novus & $\begin{array}{l}\text { NB100- } \\
479\end{array}$ & $4{ }^{\circ} \mathrm{C}$ \\
\hline $\begin{array}{l}\text { Anti-Vinculin } \\
\text { hVIN-1) }\end{array}$ & $\begin{array}{l}\text { Maus } \\
\text { monoklonal }\end{array}$ & $1: 10000$ & $\begin{array}{l}\text { Sigma } \\
\text { Aldrich }\end{array}$ & V9264 & $-20{ }^{\circ} \mathrm{C}$ \\
\hline Sekundäre Antikörper & \multicolumn{5}{|l|}{} \\
\hline Anti-mouse HRP & Ziege & $1: 1000$ & SantaCruz & sc-2005 & $4{ }^{\circ} \mathrm{C}$ \\
\hline Anti-rabbit HRP & Ziege & $1: 30000$ & SantaCruz & sc-2004 & $4^{\circ} \mathrm{C}$ \\
\hline
\end{tabular}

\subsubsection{RNA-Isolation}

Für die Isolation von RNA wurden zunächst Zellen in einer Konzentration von $1 \times 10^{5}$ Zellen/ml in Zellkulturschalen mit $4 \mathrm{~cm}$ Durchmesser ausgesät. Eine Gruppe der Zellen verblieb für $48 \mathrm{~h}$ im normoxischen $\left(20 \% \mathrm{O}_{2}\right)$ Brutschrank, die andere Gruppe wurde nach $24 \mathrm{~h}$ für weitere $24 \mathrm{~h}$ in die Hypoxie-Box $\left(1 \% \mathrm{O}_{2}\right)$ umgesetzt.

Bei der anschließenden Isolation wurden die Zellen jeder Zellkulturschale in $500 \mu$ TrizolReagenz aufgenommen. Als nächstes wurde jeder Probe $100 \mu$ l Chloroform zugegeben, sie wurde für 15 Sekunden invertiert und inkubierte dann für 2-3 min bei Raumtemperatur. Nach einem Zentrifugationsschritt von $11400 \mathrm{rpm}$ bei $4{ }^{\circ} \mathrm{C}$ für $15 \mathrm{~min}$ wurde die wässrige Oberphase, die die RNA enthält, in ein Reaktionsgefäß überführt. Die Probe wurde gevortext und es folgte die Zugabe des gleichen Volumens an Isopropanol zur Präzipitation der RNA. Nach 10 min Inkubationszeit bei RT wurde die Probe erneut für $10 \mathrm{~min}$ bei $11400 \mathrm{rpm}$ und $4{ }^{\circ} \mathrm{C}$ zentrifugiert. Das Präzipitat wurde mit $500 \mu 1$ 75\%igem Ethanol gewaschen, anschließend wurde das Pellet bei Raumluft getrocknet und in $10 \mu \mathrm{DEPC}-\mathrm{H}_{2} \mathrm{O}$ aufgenommen. Mit dem Spektrophotometer konnte anhand der optischen Dichte bei 260 und $280 \mathrm{~nm}$ die Konzentration und Reinheit der RNA bestimmt werden. Die Proben wurden bei $-80{ }^{\circ} \mathrm{C}$ gelagert. 


\subsubsection{9 cDNA-Synthese}

Die Bildung von komplementärer DNA (cDNA) aus isolierter RNA erfolgte durch das virale Enzym Reverse Transkriptase, eine RNA-abhängige DNA-Polymerase. Entgegen der üblichen Prozessrichtung (revers) von Polymerasen binden spezifische Oligo(dT) ${ }_{18}$-Primer das 3‘-Ende der mRNA, sodass der cDNA-Strang vom 3‘ zum 5‘ Ende synthetisiert wurde.

Ein Gemisch aus $2 \mu \mathrm{g}$ RNA und $1 \mu \mathrm{l}$ Oligo(dT) ${ }_{18}$-Primer wurde mit DEPC- $\mathrm{H}_{2} \mathrm{O}$ auf ein Gesamtvolumen von $11 \mu \mathrm{l}$ aufgefüllt, für $10 \mathrm{~min}$ bei $65^{\circ} \mathrm{C}$ inkubiert und danach auf $4{ }^{\circ} \mathrm{C}$ abgekühlt. Anschließend wurde dem Ansatz folgender Reaktionsmix zugegeben: $1 \mu$ Ribolock (RNase Inhibitor), $2 \mu \mathrm{l}$ Reverse Transkriptase (20 U/ $\mu \mathrm{l}), 2 \mu 110 \mathrm{mM}$ dNTP-Mix sowie $4 \mu \mathrm{l}$ Reaktionspuffer (5x). Einer einstündigen Inkubation bei $37^{\circ} \mathrm{C}$, in der die Synthese der cDNA stattfand, folgte ein Erhitzen des Ansatzes für $10 \mathrm{~min}$ auf $65^{\circ} \mathrm{C}$ wodurch die Reverse Transkriptase inaktiviert wurde. Die cDNA wurde schließlich bei $-20{ }^{\circ} \mathrm{C}$ gelagert.

\subsubsection{Quantitative Echtzeit-Polymerase-Kettenreaktion}

Die qRT-PCR beruht auf dem Prinzip der Polymerase-Kettenreaktion, einer Methode zur Vervielfältigung von DNA-Abschnitten. Hierbei wird vielfach derselbe Zyklus durchlaufen, der aus Denaturierung der Doppelstrang DNA, Anlagern des spezifischen Primers (Annealing) und der Elongation des DNA-Stücks durch die hitzestabile Taq-Polymerase besteht.

Zusätzlich wird in der qRT-PCR durch Fluoreszenzmarkierung die Menge des amplifizierten Produkts in jedem Zyklus gemessen.

Als fluoreszierender Marker wurde SYBR Green I genutzt, das mit DNA interkaliert und bei der Bindung doppelsträngiger DNA fluoresziert. Als Referenzfarbstoff diente ROX ${ }^{\mathrm{TM}}$.

Die gemessenen Werte der Genproben wurden in L929- und C2C12-Zellen auf das Housekeeping-Gen mS12 abgeglichen, um Abweichungen im cDNA-Gehalt der einzelnen Proben herausrechnen zu können. In Untersuchungen am Nematoden C. elegans diente das Haushaltsgen y45f10d.4 als Abgleich. Der qRT-PCR Reaktionsansatz enthielt je Probe $1 \mu 1$ cDNA, 12,5 $\mu$ l Sensi Mix SYBR Low Rox (2x), jeweils 0,5 $\mu$ l forward- und reverse-Primer

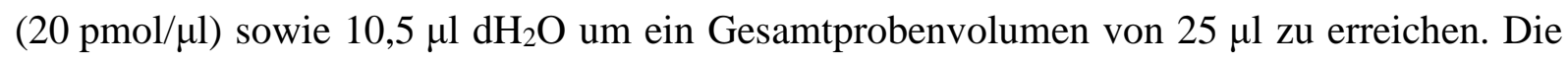
Liste der benutzten Primer und das Thermalprofil der qPCR sind in Tabelle 3 und 4 aufgeführt. 
Tabelle 3: Übersicht der verwendeten Primer

\begin{tabular}{|l|l|l|}
\hline Name & Sequenz & $\begin{array}{l}\text { Annealing- } \\
\text { Temperatur }\end{array}$ \\
\hline mS12for & GAAGCTGCCAAGGCCTTAGA & $60{ }^{\circ} \mathrm{C}$ \\
\hline mS12rev & AACTGCAACCAACCACCTTC & $60{ }^{\circ} \mathrm{C}$ \\
\hline Arhgap19mus fw & GGCTTATCAAGCGCAAAGTCC & $58^{\circ} \mathrm{C}$ \\
\hline Arhgap19mus re & CCCTCTCTCTTCGCCTCAGA & $58^{\circ} \mathrm{C}$ \\
\hline mmArhgef19_fw & ACGGACCGAAAGTGAGAAGC & $62^{\circ} \mathrm{C}$ \\
\hline mmArhgef19_rev & GCCTGCTTGGATCTGACACT & $62^{\circ} \mathrm{C}$ \\
\hline mmArhgap29_fw & ATCTGAGGCGAGTGGTGGAT & $58^{\circ} \mathrm{C}$ \\
\hline mmArhgap29_rev & AGCAGCTTGGGGCTTTTACA & $58^{\circ} \mathrm{C}$ \\
\hline mmArhgap28_fw & AGTCAAGCAGTACCGCGAAG & $61^{\circ} \mathrm{C}$ \\
\hline mmArhgap28_rev & GCTGAAGAACAAGTTGGGCG & $61^{\circ} \mathrm{C}$ \\
\hline Worm Spv-1 Fw 1 & ATGTCGTCGACGAGCAGTATATG & $62^{\circ} \mathrm{C}$ \\
\hline Worm Spv-1 Rev1 & CTTCTACTCGGCGTATGATG & $62^{\circ} \mathrm{C}$ \\
\hline Worm Egln9 fw1 & GATGACTGTGAGATCGACAAG G & $62^{\circ} \mathrm{C}$ \\
\hline Worm Egln9 rev1 & CACTACTGAACGGTACTGTAC & $62^{\circ} \mathrm{C}$ \\
\hline Worm fw y45f10d.4 & CGAGAACCCGCGAAATGTCGGA & $62{ }^{\circ} \mathrm{C}$ \\
\hline Worm rev y45f10d.4 & CGGTTGCCAGGGAAGATGAGGC & $62^{\circ} \mathrm{C}$ \\
\hline
\end{tabular}

Tabelle 4: Thermalprofil der qRT-PCR

\begin{tabular}{|l|l|l|l|}
\hline Schritt & Temperatur $\left[{ }^{\circ} \mathrm{C}\right]$ & Zeit $[\mathrm{min}]$ & Anzahl Zyklen \\
\hline Prä-Denaturierung & 95 & $10: 00$ & 1 \\
\hline Denaturierung & 95 & $00: 30$ & 40 \\
\hline Annealing (Messung) & $\begin{array}{l}\text { Je Primer } \\
\text { verschieden (s.Tab.3) }\end{array}$ & $00: 20$ & 40 \\
\hline Elongation & 72 & $00: 30$ & 40 \\
\hline Denaturierung & 95 & $01: 00$ & 1 \\
\hline Annealing (Messung) & $\begin{array}{l}\text { Je Primer } \\
\text { verschieden (s.Tab.3) }\end{array}$ & $00: 30$ & 1 \\
\hline Ende & 95 & $00: 30$ & 1 \\
\hline
\end{tabular}

\subsubsection{Caenorhabditis elegans}

\subsubsection{Caenorhabditis elegans-Stämme}

An dem Modellorganismus C. elegans wurden Experimente zur physiologischen Rolle von ArhGAP29 durchgeführt. C. elegans ist unter anderem wegen seiner Zellkonstanz (Eutelie) sowie der einfachen Handhabung im Labor ein häufig genutzter Modellorganismus. Es wurden ein Wildtypstamm (N2), ein HIF-1 Mutantenstamm (ZG31, generiert von Jiang/PowellCoffman, Iowa, USA) und ein Spv-1 knock-out Stamm (generiert von der OMRF Knock-out Group, Oklahoma City, USA) verwendet. Die Stämme wurden freundlicherweise von Prof. Dr. Schnabel von der Technischen Universität Braunschweig zur Verfügung gestellt. 


\subsubsection{Caenorhabditis elegans Haltung}

C. elegans wurden auf $10 \mathrm{~cm}$ Durchmesser Platten mit NGM-Agar kultiviert. Nach dem Gießen und Aushärten der Platten wurden diese aus einer Flüssigkultur mit E. coli OP50 als C. elegans Nahrung beimpft. Etwa alle vier Wochen wurden die Nematoden auf eine frische Platte umgesiedelt. Hierfür wurde mit einer abgeflammten Rasierklinge ein Stück des besiedelten Agars aus der Platte geschnitten und mit der Oberseite nach unten auf eine frische Platte transferiert. Die besiedelten Platten wurden bei $15^{\circ} \mathrm{C}$ verwahrt. Experimente wurden bei RT durchgeführt.

\subsubsection{Bestimmung der Eiablageanzahl von Caenorhabditis elegans}

Mithilfe eines selbst hergestellten „Wurmpickers“ (ein mit einer Kneifzange am Ende abgeflachter Platindraht, der an einer Glaspipette festgeschmolzen wurde) wurden einzelne Würmer im L4-Larvenstadium auf eine 3,5 cm Durchmesser NGM-Agarplatte mit zentralem, ringförmigen E.coli OP50-Bewuchs gesetzt. Nach Beginn der Reproduktionszeit wurden die Tiere täglich zur gleichen Zeit auf frische Nährplatten übersiedelt und die verbliebenen Eier und Larven mithilfe eines Rasters gezählt.

\subsubsection{RNA-Isolation aus Caenorhabditis elegans}

Von jeweils zwei Platten wurden die synchronisierten adulten Würmer mit $4 \mathrm{ml}$ M9-Puffer abgespült und in ein $15 \mathrm{ml}$ Falcon überführt. Die Würmer wurden kurz abzentrifugiert (1 min, 2000 rpm), der Überstand wurde entfernt und die Würmer wurden erneut mit 5 ml M9-Puffer gewaschen. Im Anschluss wurden die Würmer in $5 \mathrm{ml}$ M9-Puffer für $1 \mathrm{~h}$ wippend inkubiert, zentrifugiert und der Überstand verworfen. Das Wurmpellet wurde mit $1 \mathrm{ml}$ Trizol versetzt und die RNA isoliert (siehe RNA Isolation Kapitel 2.2.1.8, S 25).

\subsubsection{Verwendete Computerprogramme}

Die Auswertung der qRT-PCR-Daten wurde mit Graph Pad Prism 5 durchgeführt, wobei die statistische Analyse durch ungepaarte, zweiseitige T-Tests erfolgte. Als Signifikanzlevel wurden $\mathrm{p}<0,05=*, \mathrm{p}<0,01=* *$ und $\mathrm{p}<0,001=* * *$ gewählt. Die Ergebnisse wurden als Mittelwert \pm Standardfehler (mean \pm standard error of the mean $(\mathrm{SEM})$ ) angegeben. Die grafische Darstellung der qRT-PCR-, Western Blot- sowie Immunfluoreszens-Ergebnisse erfolgte durch Corel Draw X5 und Adobe Photoshop CS4. Mit dem Programm ImageJ wurde die Größe der Zellen gemessen. Für die Textverarbeitung und das Literaturverzeichnis wurden Microsoft Office Word 2010 bzw. EndNote X5 verwendet. Die schematischen Abbildungen in Einleitung und Diskussion wurden mit dem Programm Inkscape 0.91 erstellt. 


\section{Ergebnisse}

\subsection{Regulation von GAPs und GEFs in Hypoxie}

In vorherigen Untersuchungen wurden bei einem unvoreingenommenen Transkriptomscreen unter Hypoxie abweichende Expressionsmuster für einige Gene identifiziert, die für Rho-regulierende GAPs und GEFs codieren (durchgeführt von Dr. Liza Swain, Institut für Herz- und Kreislaufphysiologie, Georg August Universität Göttingen).

Um eine hypoxische Regulation der erhaltenen Kandidatengene näher zu untersuchen, wurden im Folgenden die mRNA-Level des ArhGEF19-, ArhGAP19-, ArhGAP28- (Abb. 7) sowie des ArhGAP29-Gens (Abb.7 und 8) mittels qRT-PCR analysiert. Diese Experimente wurden in einer L929-Fibrosarkom-Zelllinie (Abb.7) sowie in einer C2C12-Myoblasten-Zelllinie (Abb. 8) durchgeführt, beides sind immortalisierte Mauszelllinien. In Wt-Zellen dieser Zelllinien wurde verglichen, in welcher Weise die Kandidatengene nach 24 h Hypoxie $\left(1 \% \mathrm{O}_{2}\right)$ im Gegensatz zu 24 h Normoxie $\left(20 \% \mathrm{O}_{2}\right)$ ihre Expression verändern. Parallel wurde die HIF$1 \alpha$-Abhängigkeit einer möglichen hypoxischen Induktion mittels eines HIF-1 $\alpha$-knock-downL929-Zellklons analysiert (shHIF-1 $\alpha$-Zellen). ShHIF-1 $\alpha$-Zellen wurden mittels stabiler lentiviraler Transduktion mit einem short-hairpin (sh)-Konstrukt behandelt, welches aufgrund seiner spezifischen Basenfolge durch RNA-Interferenz eine stabile Stilllegung des HIF-1 $\alpha$ Gens verursacht. Sh-Kontrollzellen wurden der gleichen Prozedur unterzogen, exprimieren jedoch lediglich eine „non-target-shRNA“, die keine Veränderung der Genexpression bewirkt (Vogler et al. 2013). 
A

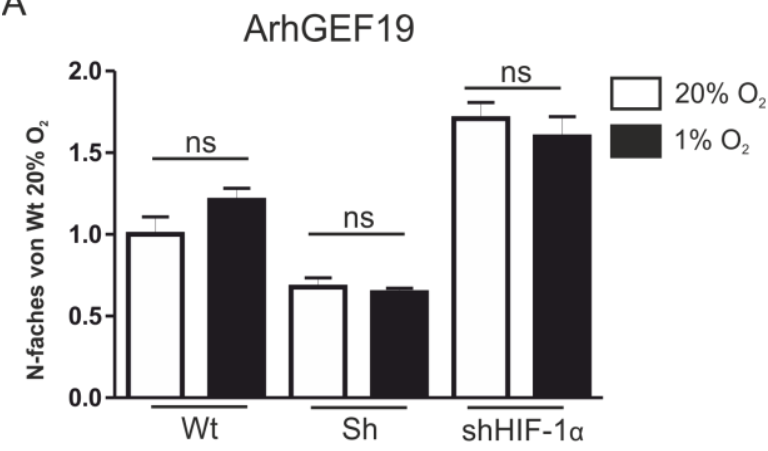

C

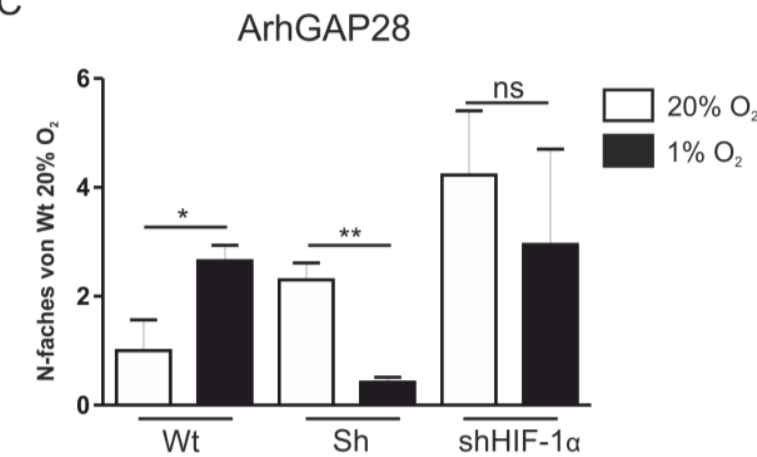

B

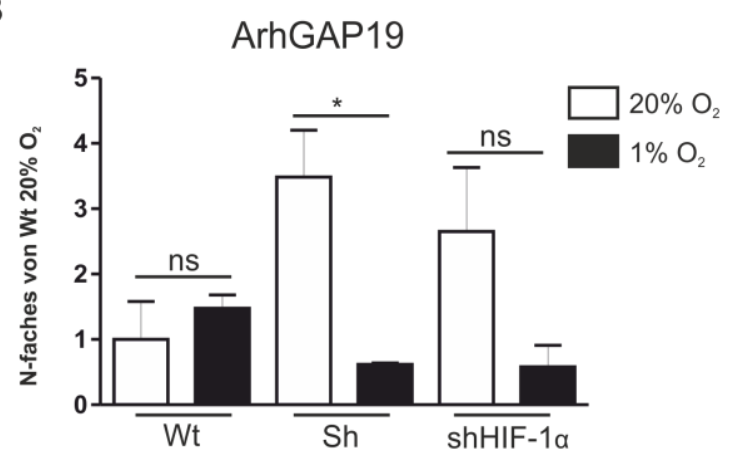

$\mathrm{D}$

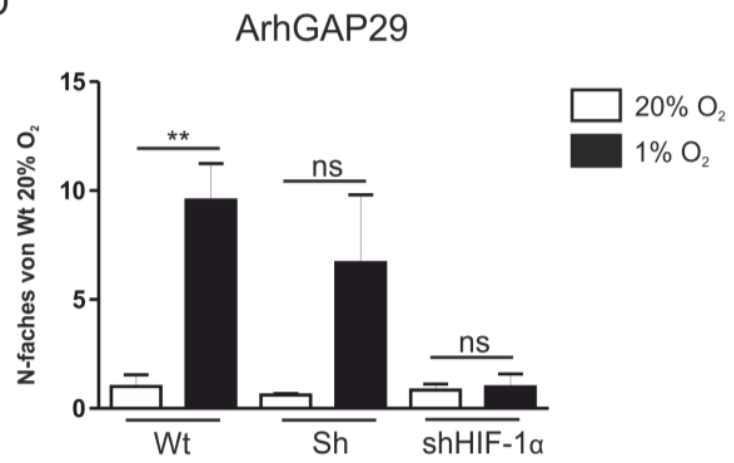

Abb. 7: Veränderung der Genexpression Rho-regulierender Proteine in Hypoxie. Die Grafik zeigt Veränderungen der mRNA-Expression des (A) ArhGEF19-, (B) ArhGAP19-, (C) ArhGAP28- und (D) ArhGAP29-Gens in L929-Fibroblasten nach $24 \mathrm{~h}$ hypoxischer Inkubation $\left(1 \% \mathrm{O}_{2}\right)$ verglichen mit normoxischer Inkubation $\left(20 \% \mathrm{O}_{2}\right)$. Die Messung erfolgte in Wt-, Sh-Kontroll- und HIF-1 $\alpha$-knock-down-Zellen. Erklärung: Wt - Wildtyp, Sh - short-hairpin-Kontrolle, shHIF-1 $\alpha$ - HIF-1 $\alpha$-knock-down-Zellen; ns - nicht signifikant; * - p <0,05; ** - $\mathrm{p}<0,01 ;$ Mittelwert \pm Standardfehler; $\mathrm{n}=4$.

Des Weiteren wurden L929-Wt-Zellen mit dem PHD-Inhibitor DMOG behandelt (Abb. 8B), um HIF- $1 \alpha$ in Normoxie zu stabilisieren und die daraus resultierenden Effekte mit denen hypoxischer Zellen zu vergleichen.

A

ArhGAP29

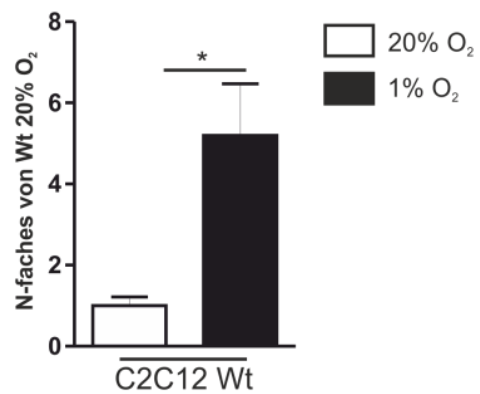

B

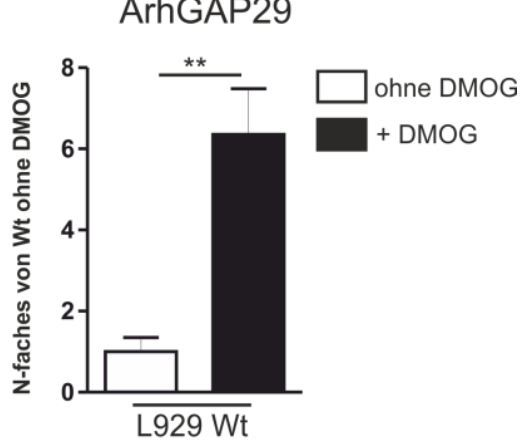

Abb. 8: Induktion von ArhGAP29-mRNA in C2C12-Myoblasten und in L929-Fibroblasten nach DMOGBehandlung. (A) zeigt die veränderte Genexpression des ArhGAP29-Gens in C2C12-Myoblasten nach $24 \mathrm{~h}$ Hypoxie $\left(1 \% \mathrm{O}_{2}\right)$ im Vergleich zu normoxisch $\left(20 \% \mathrm{O}_{2}\right)$ gehaltenen Zellen. In (B) ist die ArhGAP29-mRNAExpression in unbehandelten L929-Fibroblasten sowie nach Inkubation der Zellen mit dem PHD-Inhibitor DMOG für 24 h zu sehen. Erklärung: Wt - Wildtyp, DMOG - Dimethyloxaloylglycin; * - p <0,05; ** - p <0,01; Mittelwert \pm Standardfehler; $\mathrm{n}=4$. 
In Tabelle 5 ist zu sehen, welche Kandidatengene in welcher Zelllinie in Hypoxie (bzw. durch Behandlung mit DMOG) verglichen mit normoxischen Zellen vermehrt oder vermindert transkribiert wurden. Die Gene ArhGEF19 und ArhGAP19 zeigten in den verschiedenen Zellreihen keine konstanten Veränderungen ihrer mRNA-Level in Hypoxie und wurden daher nicht weiter untersucht. Sowohl ArhGAP28 als auch ArhGAP29 wiesen dagegen eine signifikante hypoxische Induktion in L929-Wildtypzellen auf. Da in den L929-ShKontrollzellen für ArhGAP28 eine signifikante Abnahme der Genexpression, für ArhGAP29 jedoch der Trend für eine Zunahme der Genexpression festgestellt wurde, sollte die ArhGAP29Expression in Abhängigkeit von Hypoxie und dem HIF-1-Signalweg näher untersucht werden. Die hypoxische Induktion von ArhGAP29 ist nur in Wildtyp- und Sh-Kontrollzellen zu beobachten, im HIF-1 $\alpha$-knock-out-Klon bleibt sie aus. Dies weist darauf hin, dass die Expression von ArhGAP29 HIF-1 $\alpha$-abhängig ist. In Abbildung 8 zeigte sich auch in C2C12Zellen eine hypoxische Induktion des ArhGAP29-Gens, weiterhin konnte in L929Wildtypzellen eine signifikante Erhöhung des mRNA-Expressionslevels nach DMOGBehandlung und normoxischer Stabilisierung von HIF-1 $\alpha$ festgestellt werden.

Tabelle 5: Übersicht der veränderten Genexpression Rho-regulierender Proteine. Zusammenfassung der in Abb. 7 und 8 gezeigten qPCR-Ergebnisse. Veränderung der Genexpression verschiedener GAPs und GEFs nach $24 \mathrm{~h}$ hypoxischer Inkubation $\left(1 \% \mathrm{O}_{2}\right)$ bzw. nach DMOG-Zugabe (bei 20\% $\mathrm{O}_{2}$ ) verglichen mit normoxischer Inkubation $\left(20 \% \mathrm{O}_{2}\right)$. Erklärung: Wt - Wildtyp, Sh-Kontr. - short-hairpin-Kontrolle, shHIF-1 $\alpha$ - HIF-1 $\alpha$-knockdown-Zellen, $\uparrow$ - gesteigerte Expression, $\downarrow$ - verminderte Expression, $\rightarrow$ - keine signifikante Änderung, ,,-”nicht untersucht.

\begin{tabular}{|c|c|c|c|c|c|}
\hline \multirow{2}{*}{$\begin{array}{c}\text { Kandidaten- } \\
\text { Gen }\end{array}$} & \multicolumn{5}{|c|}{ Zellinie } \\
\cline { 2 - 6 } & Wt & Sh-Kontr. & shHIF-1 $\alpha$ & $\begin{array}{c}\text { Wt 20\% } \\
\text { +DMOG }\end{array}$ & Wt \\
\hline ArhGEF19 & $\rightarrow$ & $\rightarrow$ & $\rightarrow$ & - & - \\
\hline ArhGAP19 & $\rightarrow$ & $\downarrow$ & $\rightarrow$ & - & - \\
\hline ArhGAP28 & $\uparrow$ & $\downarrow$ & $\rightarrow$ & - & - \\
\hline ArhGAP29 & $\uparrow$ & $\rightarrow$ & $\rightarrow$ & $\uparrow$ & $\uparrow$ \\
\hline
\end{tabular}


Im Folgenden wurden Western-Blot-Experimente durchgeführt, um eine hypoxische Induktion von ArhGAP29 auch auf Proteinebene zu analysieren und weiterhin diese hypoxische Induktion auf die Abhängigkeit von HIF-1 $\alpha$ zu testen (Abb. 9A und B).

A

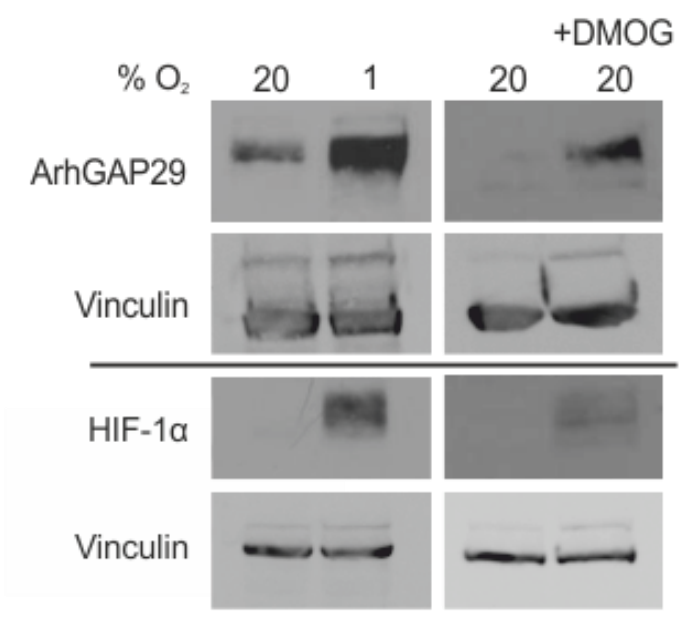

B

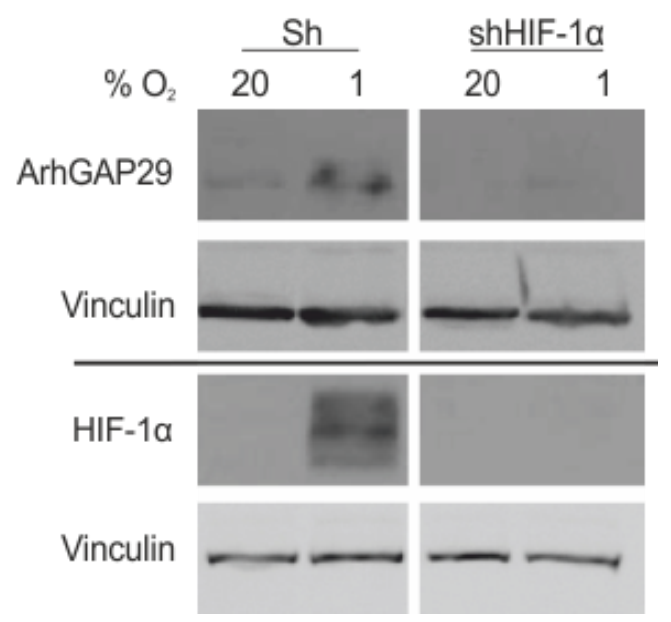

Abb. 9: Hypoxie und DMOG-Behandlung induzieren ArhGAP29 auf Proteinebene; die hypoxische Induktion von ArhGAP29 erfolgt HIF-1a-abhängig. Western Blot mit Zelllysaten von L929-Fibroblasten, die für $24 \mathrm{~h}$ bei $20 \%$ bzw. $1 \% \mathrm{O}_{2}$ inkubiert oder mit DMOG behandelt wurden. (A) In Hypoxie sowie nach DMOGBehandlung sind in L929-Wildtypzellen erhöhte Proteinlevel von ArhGAP29 und die hypoxische Stabilisierung von HIF-1 $\alpha$ zu sehen. (B) L929-Sh-Kontrollzellen (Sh) zeigen unter Hypoxie ebenfalls eine Induktion von ArhGAP29 und HIF-1 $\alpha$, diese Induktion bleibt in HIF-1 $\alpha$-knock-down-Zellen (shHIF-1 $\alpha$ ) jedoch aus.

In Abb. $9 \mathrm{~A}$ ist das Ergebnis des Versuchs mit Zelllysaten von L929-Fibroblasten zum Nachweis von ArhGAP29- und HIF-1 $\alpha$-Proteinen zu sehen. Die Zellen wurden hypoxisch inkubiert bzw. mit DMOG behandelt. Es zeigt sich, dass sowohl durch Hypoxie als auch durch Behandlung mit dem PHD-Inhibitor DMOG vermehrt ArhGAP29 exprimiert werden. HIF-1 $\alpha$ wird durch Sauerstoffmangel und DMOG erwartungsgemäß ebenfalls stabilisiert. Die Ergebnisse des Western Blots stimmen demnach mit den vorangegangenen Befunden aus den qRT-PCR-Experimenten überein. Im Western Blot in Abb. 9 B ist eine Hochregulation des ArhGAP29-Proteins auch in hypoxischen Sh-Kontrollzellen zu sehen. Der HIF-1 $\alpha$-knockdown-Klon zeigt jedoch keine vermehrte Expression von ArhGAP29 unter Hypoxie. Auch für HIF-1 $\alpha$ zeigt sich eine deutliche Bande alleine in den Sh-Kontrollzellen. Dies bestätigt zusammen mit den qPCR-Ergebnissen, dass die hypoxische Induktion von ArhGAP29 abhängig von HIF-1 $\alpha$ geschieht.

\subsection{Zeitliche Dynamik der Genexpression von ArhGAP29}

Im Folgenden wurde mittels qRT-PCR die zeitliche Dynamik der Genexpression von ArhGAP29 untersucht, um einen Eindruck von der zeitlichen Dimension der hypoxischen Induktion von ArhGAP29 zu bekommen. Dafür wurde die ArhGAP29-mRNA-Expression in 
L929-Fibroblasten nach 2, 4, 8 und 12 Stunden in Hypoxie gemessen und mit der mRNA von 12 Stunden normoxisch inkubierten L929-Fibroblasten verglichen. Bereits nach 2 Stunden zeigte sich eine signifikante Erhöhung des ArhGAP29-mRNA-Levels mit steigenden Werten bis zu einem Höchstwert um 8 Stunden (Abb. 10). Nach 12 Stunden fiel die mRNA-Expression wieder leicht ab, war jedoch nach wie vor signifikant erhöht.

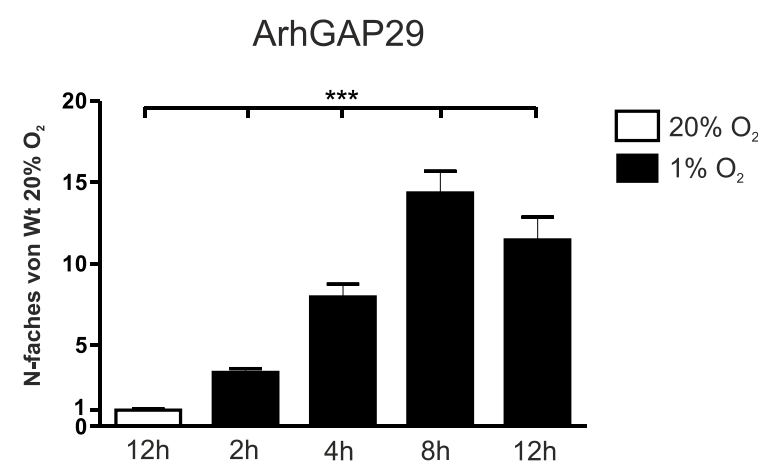

Abb. 10: Hypoxische Induktion von ArhGAP29 im Zeitverlauf. L929-Zellen wurden für 12 Stunden in Normoxie $\left(20 \% \mathrm{O}_{2}\right)$ bzw. für 2, 4, 8 oder 12 Stunden in Hypoxie $\left(1 \% \mathrm{O}_{2}\right)$ inkubiert. Das mRNA-Expressionslevel von ArhGAP29 wurde anschließend mittels qRT-PCR analysiert. *** $-\mathrm{p}<0,001$; Mittelwert \pm Standardfehler; $\mathrm{n}=4$.

\subsection{Etablierung eines ArhGAP29-knock-downs in L929-Fibroblasten}

Um in weiteren Versuchen einen Einblick in die zellulären Funktionen von ArhGAP29 zu gewinnen, wurden zwei unabhängige, stabile ArhGAP29-knock-down-Zelllinien mittels lentiviralem shRNA-Transfer generiert, die im Folgenden mit Kd1 und Kd2 benannt sind. Der Knock-down von ArhGAP29 wurde auf mRNA- und Proteinebene analysiert. In Abb. 11A sind die mRNA-Level von ArhGAP29 in Wildtypzellen, Sh-Kontrollzellen sowie den ArhGAP29knock-down-Klonen Kd1 und Kd2 sowohl in Normoxie als auch nach 24 Stunden hypoxischer Inkubation zu sehen. Die qRT-PCR-Analyse zeigt eine signifikant verminderte hypoxische Genexpression von ArhGAP29 in beiden ArhGAP29-knock-down-Zellklonen gegenüber den Wildtyp- und Sh-Kontrollzellen. Dazu passend ist im Western Blot in Abb.11B eine Expression von ArhGAP29-Protein in den hypoxisch inkubierten Wildtypzellen und in Sh-Kontrollzellen zu sehen. Kd1 sowie Kd2 zeigen keine hypoxische Hochregulation des ArhGAP29-Proteins. Ein Knock-down des ArhGAP29-Gens konnte somit auf mRNA- und Proteinebene nachgewiesen werden. 
A

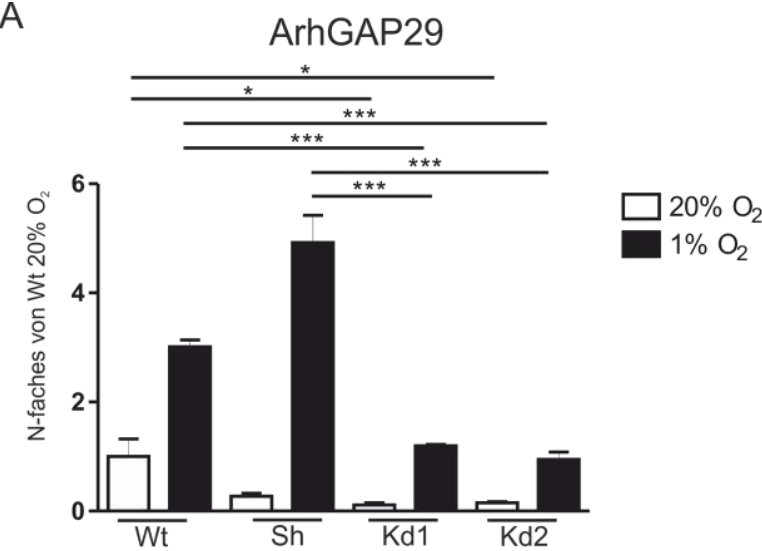

B

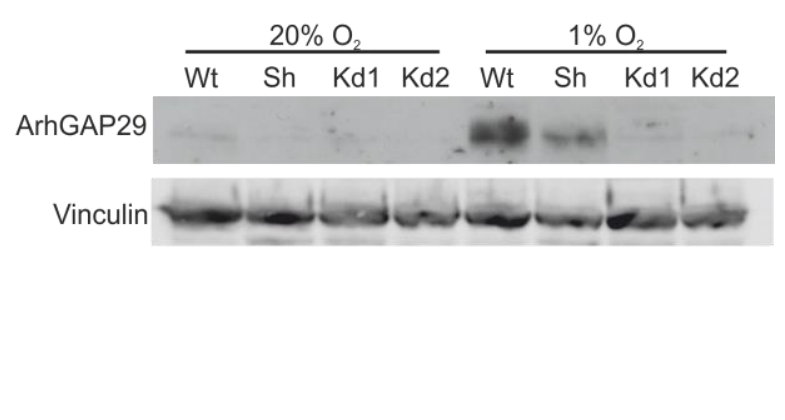

Abb. 11: Knock-down von ArhGAP29 in L929-Zellen. Durch lentivirale Transduktion spezifischer Sh-Sequenzen wurden stabile ArhGAP29-knock-down-Zellklone erstellt (Kd1 und Kd2). (A) QRT-PCR Daten zeigen eine signifikant geringere hypoxische Induktion von ArhGAP29 in Kd1 und Kd2 im Vergleich zu Wildtyp(Wt) und Sh-Kontrollzellen (Sh). (B) Im Western Blot ist ebenso eine deutliche hypoxische Induktion von ArhGAP29 nur in Wt- und Sh-Zellen zu sehen. *** $-\mathrm{p}<0,001$; Mittelwert \pm Standardfehler; $\mathrm{n}=4$.

\subsection{Veränderungen der Zellmorphologie in ArhGAP29-knock-down-Zellen}

Durch die Etablierung zweier L929-Fibroblasten-Zelllinien mit stabilem ArhGAP29knock-down ergab sich die Möglichkeit, die Auswirkung der hypoxischen ArhGAP29Induktion im Vergleich zu L929-Wt-Zellen hinsichtlich Morphologie und Funktion genauer zu untersuchen. Hierzu wurden normoxisch und hypoxisch inkubierte L929-Wt-, Sh-Kontroll- und ArhGAP29-knock-down (Kd2)-Zellen mittels Phalloidinfärbung und anschließender Fluoreszenzmikroskopie beurteilt (Abb. 12A). Die Wildtyp- und Sh-Kontrollzellen hatten unter hypoxischen Bedingungen eine veränderte Zellmorphologie mit vermehrter Ausbildung von Pseudopodien, kontraktilen Aktomyosinbündeln (stress fibres) und einer rundlichen Zellform. Zudem zeigte das Ausmessen der Zellen eine signifikant verbreiterte Zellfläche unter hypoxischen Bedingungen (Abb. 12B). Diese Effekte entsprechen den 2013 bereits von Vogler et al. beschriebenen Befunden in hypoxischen L929-Fibroblasten (Vogler et al. 2013). Weiterhin fällt auf, dass bereits in Normoxie in den Kd2-Zellen ähnliche morphologische Charakteristiken mit vergrößerter Zellfläche, zahlreichen Pseudopodien und runder Gestalt zu erkennen sind. Auch eine ausgeprägte Bildung von filamentösem Aktin kann bei den normoxischen Kd2-Klonen beobachtet werden. Unter hypoxischen Bedingungen zeigen die Kd2-Zellen eine ähnliche Morphologie mit zusätzlich vergrößerter Zellfläche. 
A

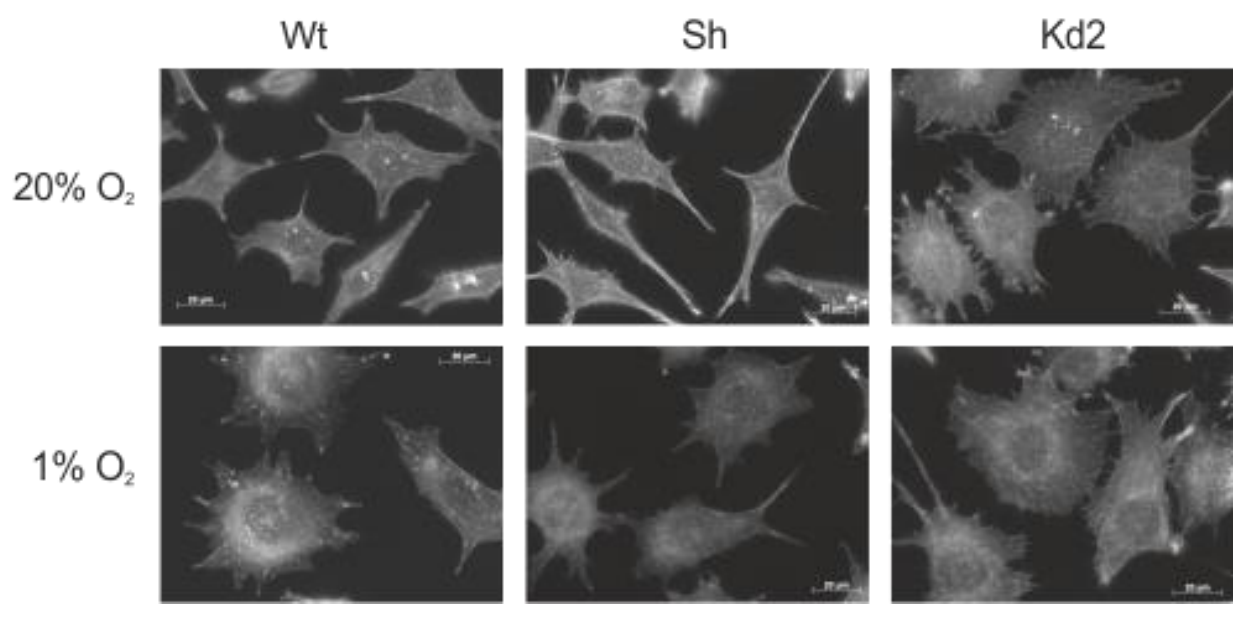

$\mathrm{B}$

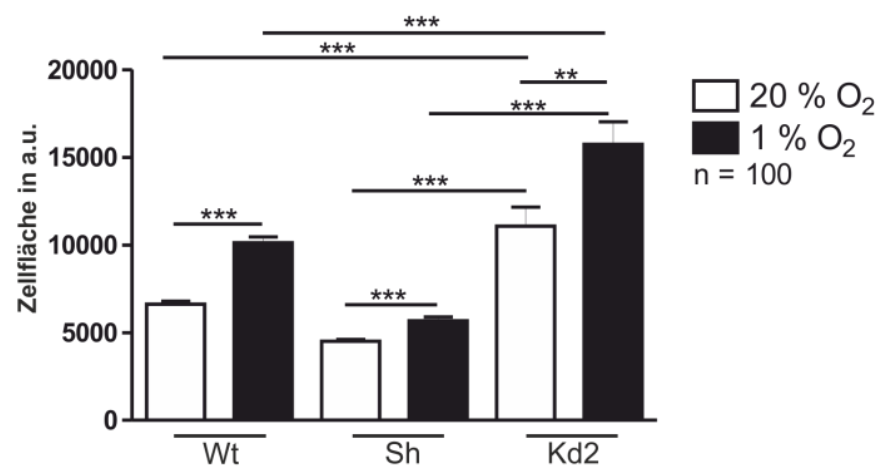

Abb. 12: Morphologische Veränderungen in L929-Fibroblasten mit ArhGAP29-knock-down. (A) Wildtyp (Wt)- Sh-Kontroll (Sh)- und ArhGAP29-knock-down (Kd2)-Zellen wurden für $24 \mathrm{~h}$ bei $20 \% \mathrm{O}_{2}$ bzw. $1 \% \mathrm{O}_{2}$ inkubiert, fixiert und mit fluoreszenzmarkiertem Phalloidin angefärbt. ArhGAP29-knock-down-Zellen zeigen sowohl in Normoxie als auch in Hypoxie morphologische Veränderungen im Vergleich zu Wt- und Sh- Zellen. Die hypoxischen Zellen sowie die normoxischen ArhGAP29-knock-down-Zellen bilden vermehrt filamentöses Aktin aus. (B) Analyse der Zellfläche von normoxisch und hypoxisch inkubierten Wt- Sh- und Kd2-Zellen. Alle Zellgruppen weisen eine signifikante Flächenzunahme nach $24 \mathrm{~h}$ Hypoxie im Vergleich zu normoxisch inkubierten Zellen auf. ArhGAP29-knock-down-Zellen sind sowohl unter 20\% als auch 1\% O2 im Vergleich zu Wt- und Sh- Zellen vergrößert. Bestimmung der Zellgröße mit ImageJ. ** - p <0,01; *** - p <0,001; Mittelwert \pm Standardfehler; $\mathrm{n}=100$.

\subsection{Die Rolle von ArhGAP29 in C. elegans}

Um zu untersuchen, ob die hypoxische Regulation von ArhGAP29 evolutionär konserviert ist, wurden in vivo-Experimente an dem Fadenwurm Caenorhabditis elegans (C. elegans) durchgeführt. Das homologe Gen zu ArhGAP29 in C. elegans heißt Spv-1 und wurde in normoxisch und hypoxisch inkubierten C. elegans-Würmern analysiert. Für die Versuche wurden folgende C. elegans-Stämme verwendet: N2 als Wildtypstamm, Zg31 als HIF-1-knockout-Stamm und RB1353 als Spv1-knock-out-Stamm.

In Abb. 13A ist eine qPCR-Analyse der relativen Expressionslevel des Spv-1-Gens in N2-Wildtypwürmern sowie in Zg31-HIF-1-knock-out-Würmern unter Normoxie und Hypoxie 
abgebildet. Im N2-Stamm ist die Expression von Spv-1 in hypoxisch inkubierten Würmern signifikant höher als die der normoxisch inkubierten Würmer. Die Analyse der Spv-1-Expression in $\mathrm{Zg} 31$-Würmern zeigt gleiche Expressionslevel bei $20 \% \mathrm{O}_{2}$ und bei $1 \% \mathrm{O}_{2}$.

Dieses Ergebnis passt zu den Befunden der Versuche in 3.1, die auf eine Abhängigkeit der ArhGAP29-Expression von HIF-1 $\alpha$ hindeuten. Der Graph in Abb. 13B zeigt eine Positivkontrolle von Eg19, was in C. elegans dem Homolog vom HIF-1 $\alpha$-Zielgen PHD2 entspricht. Es ist zu sehen, dass in Würmern des N2-Stammes eine hypoxische Induktion von Eg19 erfolgt, wie es bei einer Stabilisierung von HIF-1 $\alpha$ zu erwarten ist. Die Würmer des Zg31Stammes zeigen aufgrund des HIF-1-knock-outs hingegen keine hypoxische Induktion, vielmehr ist eine Reduktion der Genexpression zu beobachten. Zudem wurde die Eiablagerate der Würmer untersucht (Abb. 13C) Würmer mit Spv-1-Mutation zeigen mit Abstand die niedrigste Eimenge in diesem Versuch. Bei Würmern mit Knock-out des HIF-1-Gens kommt es weiterhin zu einer signifikanten Verminderung der Eiablagerate im Vergleich zu N2Würmern.

A

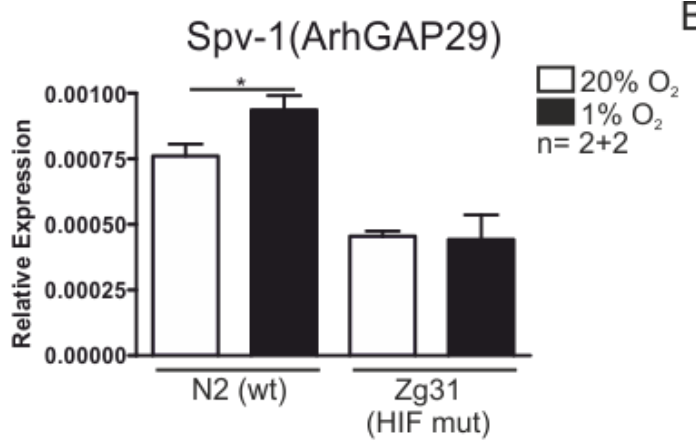

C

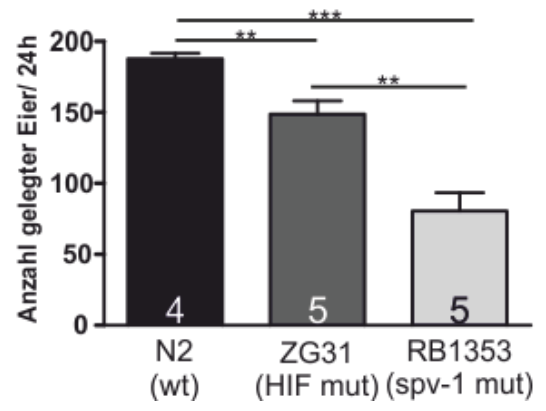

B

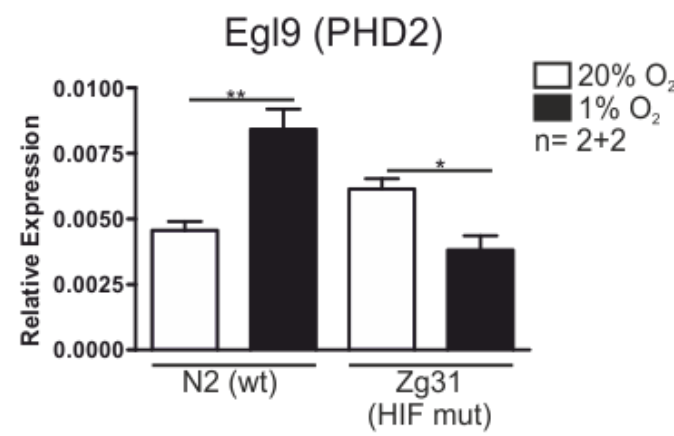

Abb. 13: ArhGAP29 in C. elegans. (A) QRT-PCR Daten zeigen eine hypoxische Induktion des ArhGAP29homologen Gens Spv-1 im Wildtypstamm N2 (wt), die im HIF-Mutantenstamm ZG31 (HIF mut) ausbleibt. (B) Positivkontrolle durch qRT-PCR Analyse des PHD2 homologen Gens Eg19 in C. elegans. Das HIF-Zielgen zeigt im Wt-Stamm N2 eine deutliche hypoxische Induktion, jedoch nicht im HIF-knock-out-Stamm ZG31. (C) Die Anzahl gelegter Eier von Spv-1-knock-out-Würmern ist signifikant niedriger als die der Wildtyp- und ZG31knock-out-Stämme. * - p <0,05; ** - p <0,01; *** - p <0,001; Mittelwert \pm Standardfehler; Zahlen in den Balken repräsentieren die Anzahl der untersuchten Würmer. 


\subsection{Zusammenfassung der Ergebnisse}

Es kann zusammengefasst werden, dass bei dem ausgewählten Kandidatengen ArhGAP29 eine hypoxische Induktion in L929-Fibroblasten und C2C12-Myoblasten festgestellt werden konnte, wohingegen bei ArhGEF19, ArhGAP19 sowie ArhGAP28 keine eindeutige Expressionsänderung in Hypoxie beobachtet wurde. Die Genexpression von ArhGAP29 erreicht nach 8 Stunden hypoxischer Inkubation ihren Spitzenwert. Weitere Versuche zeigten, dass die hypoxische Induktion abhängig vom Hypoxie-induzierbaren-Faktor-1 (HIF-1) geschieht. Ein Knock-down von ArhGAP29 in L929-Fibroblasten führt im Vergleich zu Wildtypzellen $\mathrm{zu}$ einer charakteristisch veränderten Zellmorphologie mit vergrößerter Zellfläche und der Ausbildung von filamentösem Aktin. In C. elegans-Fadenwürmern wurde eine hypoxische Hochregulation des ArhGAP29-homologen Spv-1-Gens beobachtet. Ein $C$. elegans-Stamm mit Spv-1-knock-out zeigte eine verminderte Zahl von gelegten Eiern im Vergleich zum Wildtyp. Bezüglich der in 1.8 formulierten Zielsetzung dieser Arbeit kann somit vermutet werden, dass ArhGAP29 eine wichtige Rolle in der Regulation der RhoA-Aktivität nicht nur in Normoxie, sondern auch in Hypoxie spielt. Dies wird durch die morphologischen Unterschiede, jedoch vor allem durch die Veränderung des Aktinfilamentsystems in den ArhGAP29-knock-down-Zellen in Hypoxie untermauert. 


\section{Diskussion}

Mit dieser Arbeit soll das Verständnis für Rho-regulierende Proteine bei der hypoxischen Reorganisation des Aktinzytoskeletts erweitert werden. Ist eine Zelle aus physiologischen oder pathologischen Gründen einer Minderversorgung mit Sauerstoff ausgesetzt, spricht man von Hypoxie. Dieser Zustand aktiviert in der Zelle eine Vielzahl von Mechanismen, um die Sauerstoff-Homöostase aufrechtzuerhalten. Diese werden größtenteils über den heterodimeren Transkriptionsfaktor HIF-1 vermittelt, dessen Aktivierung in der Zelle zur Expression zahlreicher Zielgene führt. Neben Mechanismen einer verbesserten Sauerstoffversorgung des Gewebes wurden auf zellulärer Ebene auch hypoxische Effekte auf das Aktinzytoskelett beobachtet (Wang und Semenza 1993; Ebert et al. 1995; Norris und Millhorn 1995; Forsythe et al. 1996). Vogler et al. konnten eine HIF-1-abhängige Neuorganisation verschiedener zytoplasmatischer Aktinisoformen in L929-Fibroblasten nachweisen. Damit einher gingen weitere morphologische und funktionelle Veränderungen, die auf eine Änderung der Aktindynamik unter Hypoxie hinweisen, wie z. B. eine verlangsamte Zellmigration, eine erhöhte Anzahl von Fokalkontakten sowie eine Zunahme der Zellfläche (Vogler et al. 2013).

Die Dynamik des Aktinzytoskeletts wird von Rho-GTPasen wie RhoA, Cdc42 und Rac1 reguliert, wobei vor allem RhoA unter Hypoxie abweichende Aktivitätsmuster zeigte (Heasman und Ridley 2008; Zieseniss 2014). Am Ende der Signalwege der Rho-GTPasen stehen zahlreiche Aktin-Dynamik-regulierende aktinbindende Proteine wie z.B. Cofilin (Matsui et al. 1996; Narumiya et al. 1997; Kaibuchi et al. 1999). Die Aktivität von Rho-GTPasen wird wiederum durch ein Regulationssystem aus aktivierenden GEFs, inhibierenden GAPs und zeitweise inaktivierenden GDIs bestimmt (Bos et al. 2007). Die Anzahl dieser regulatorischen Schalterproteine übersteigt die Zahl der Rho-GTPasen, auf die sie einwirken, etwa um den Faktor 3. Dies legt eine hohe Spezifität dieser Proteine auf Zielproteine, Gewebe und Signalwege nahe (Tcherkezian und Lamarche-Vane 2007; Cherfils und Zeghouf 2013). Vor Beginn dieser Arbeit wurde ein Makrophagen-Transkriptomscreen in Hypoxie von Dr. Liza Swain in der Arbeitsgruppe von Prof. Katschinski durchgeführt. Dadurch konnten die Kandidatengene ArhGEF19, ArhGAP19, ArhGAP28 und ArhGAP29 identifiziert werden. Diese Gene kodieren für Rho-regulierende GAPs und GEFs und zeigten eine abweichende Expression unter hypoxischen Bedingungen. Ziel war es, eine mögliche Verbindung zwischen der hypoxischen Regulation von RhoA und der Dynamik des Aktinzytoskeletts zu untersuchen. 


\subsection{Die hypoxische Induktion von ArhGAP29 ist abhängig von HIF-1 $\alpha$}

Die zuvor identifizierten Kandidaten - GAPs und GEFs - wurden auf Expressionsänderungen in hypoxischer Umgebung untersucht. Unter den Kandidatengenen ArhGEF19, ArhGAP19, ArhGAP28 und ArhGAP29 wurde für das Gen ArhGAP29 eine eindeutige hypoxische Induktion festgestellt. In L929-Fibroblasten war die Expression von ArhGAP29 in hypoxisch inkubierten Zellen auf mRNA- und Proteinebene erhöht, in C2C12-Myoblasten konnte eine Erhöhung des mRNA-Levels beobachtet werden. Dies zeigt, dass es sich hierbei um einen Zelllinien-übergreifenden Mechanismus handelt, der nicht nur in L929-Fibroblasten zu finden ist. Das ArhGAP29-Gen eignete sich daher für weitere Untersuchungen der Aktindynamik in Hypoxie.

Die hypoxische Induktion von ArhGAP29-mRNA zeigte im Zeitverlauf einen Spitzenwert nach acht Stunden hypoxischer Inkubation, war aber auch nach zwölf Stunden noch signifikant erhöht. Da HIF-1 als Haupttranskriptionsfaktor in Hypoxie die Expression zahlreicher Gene vermittelt, wurde auch eine HIF-1-Abhängigkeit der hypoxischen Induktion von ArhGAP29 in Betracht gezogen. Tatsächlich wurde im nachfolgend durchgeführten Experiment ein vermindertes hypoxisches ArhGAP29-Proteinlevel in HIF-1 $\alpha$-knock-down-Zellen beobachtet, was bestätigte, dass ArhGAP29 abhängig von HIF-1 $\alpha$ exprimiert wird. Passend dazu war ArhGAP29 nach normoxischer Stabilisation von HIF-1 $\alpha$ durch den PHD-Inhibitior DMOG ebenfalls hochreguliert.

Eine ausführliche Literaturrecherche ergab, dass von einer hypoxischen Induktion des ArhGAP29-Gens bislang nicht berichtet wurde. Es ist bekannt, dass ArhGAP29 ubiquitär exprimiert wird und als GTPase-aktivierendes Protein eine inhibitorische Wirkung auf die Aktivität von Rho-GTPasen, vor allem RhoA, besitzt (Saras et al. 1997). Eine RhoAAktivierung führt über die Rho-assoziierte-Kinase ROCK zur Ausbildung von kontraktilen Aktinfilamenten, sogenannten stress fibres, die unter anderem für die Kontraktion und Translokation von Zellen von Bedeutung sind (Ridley und Hall 1992). Zudem vermittelt RhoA über ROCK und die Lim-Kinase eine Phosphorylierung und damit die Inaktivierung des aktinbindenden Proteins Cofilin, was zur vermehrten Ausbildung von filamentösem Aktin führt (Maekawa et al. 1999). Für RhoA wurde in diversen Zelllinien eine hypoxische Aktivitätszunahme beschrieben, jedoch bestehen auch Hinweise auf eine Reduktion der RhoAAktivität unter Hypoxie (Zieseniss 2014). Unveröffentlichte Daten aus der Arbeitsgruppe von Prof. Katschinski zeigen im Zeitverlauf in Hypoxie zunächst eine erhöhte RhoA-Aktivität in L929-Fibroblasten, die nach wenigen Stunden wieder stark abnimmt. Die vorliegende Arbeit 


\title{
Diskussion
}

zeigt die Zunahme der ArhGAP29-Expression nach wenigen Stunden Hypoxie. Diese zeitliche Parallelität der Zunahme der ArhGAP29-Expression und der initial erhöhten RhoA-Aktivität lassen für ArhGAP29 eine Rolle als Feinregulator der RhoA-Aktivität vermuten (Abb. 14). Eventuell dient dieser Wirkmechanismus der Vermeidung einer überschießenden Aktivierung von RhoA.

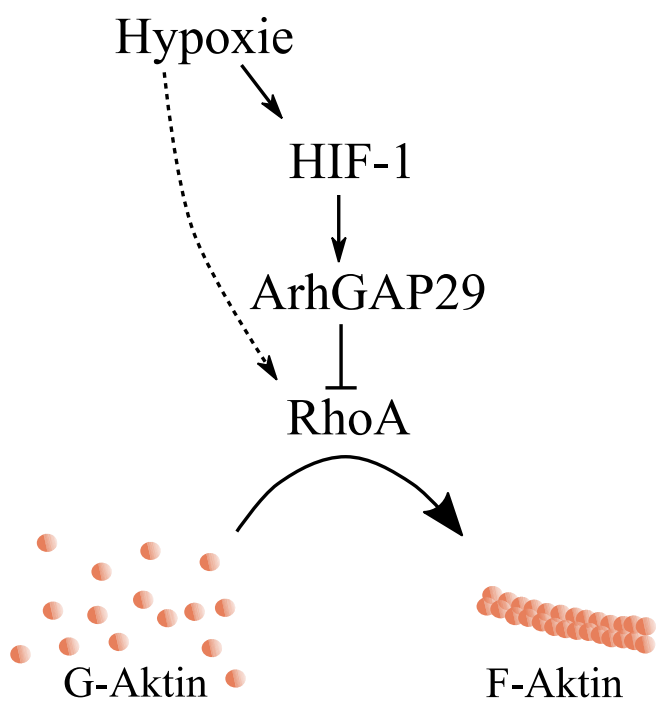

\begin{abstract}
Abb. 14: Signalweg von ArhGAP29 und RhoA in Hypoxie. Der durch Hypoxie stabilisierte Transkriptionsfaktor HIF-1 induziert ArhGAP29, das mit seiner GAP-Domäne inhibitorisch auf die RhoA-Aktivität wirkt. Gleichzeitig erfolgt eine Aktivierung von RhoA kurz nach Einsetzen der Hypoxie. Eine Funktion von ArhGAP29 zur Feinregulation der RhoA-Aktivität kann vermutet werden. Über aktinbindende Proteine vermittelt RhoA die vermehrte Ausbildung von filamentösem Aktin (F-Aktin). Erklärung: G-Aktin: globuläres Aktin.
\end{abstract}

\subsection{ArhGAP29-knock-down-Zellen zeigen morphologische Veränderungen}

Im Rahmen dieser Arbeit wurden durch das Einbringen von shRNA-Plasmidvektoren in L929Fibroblasten zwei stabile Klone mit Knock-down des ArhGAP29-Gens etabliert. Der Knockdown wurde anschließend auf mRNA- und Proteinebene überprüft. Somit bestand die Möglichkeit, über genetisch modifizierte Zellen die Folgen der verminderten ArhGAP29Expression zu analysieren. L929-Wildtypzellen, die für 24 Stunden hypoxisch inkubiert wurden, zeigten neben einer Vergrößerung der Zellfläche und einer Abrundung der Zellform deutlich mehr stress fibres als Zellen in Normoxie. Eine vergrößerte Zellfläche und die Ausbildung von stress fibres wurde in dieser Zellart unter Hypoxie bereits von Vogler et al. beschrieben (Vogler et al. 2013). ArhGAP29-knock-down-Zellen zeigten im Gegensatz zu den Wildtyp-Zellen auch in Normoxie eine deutliche Vergrößerung der Zellfläche mit vermehrter Bildung von Stressfasern. Nach hypoxischer Inkubation waren die Zellen nochmals signifikant vergrößert. Der Eindruck von vermehrten stress fibres lässt sich möglicherweise dadurch 


\section{Diskussion}

erklären, dass durch den ArhGAP29-knock-down eine Zunahme der RhoA-Aktivität sowohl in Normoxie als auch in Hypoxie resultiert.

\subsection{ArhGAP29 in mehrzelligen Organismen}

Um weitere Informationen über die Rolle von ArhGAP29 in mehrzelligen Organismen zu erhalten, wurden In-vivo-Experimente am Fadenwurm C. elegans durchgeführt. Würmer vom Wildtyp (N2) zeigten nach hypoxischer Inkubation im Vergleich zu normoxisch gehaltenen Würmern einen signifikanten Anstieg des ArhGAP29-homologen Gens Spv-1 (spermatheca physiology variant-1). Interessanterweise blieb in Würmern mit Knock-out des HIF-1-Gens (Zg31) eine Hochregulation von Spv-1 unter Hypoxie aus. In C.-elegans-Würmern erfolgt also ebenso wie in L929-Fibroblasten eine Hochregulation des Rho-regulierenden Proteins Spv-1 (ArhGAP29) unter hypoxischen Bedingungen, wobei eine Abhängigkeit von HIF-1 in Betracht gezogen werden kann. Des Weiteren konnte in Wildtypwürmern (N2) eine hypoxische Induktion des HIF-1-Zielgens PHD2 (in C. elegans: Eg19) beobachtet werden, die in HIF-1knock-out-Würmern nicht eintritt. Es kann daher als Kontrolle für die HIF-1-Expression im C.elegans-Wildtyp (N2)- und im HIF-1-knock-out (ZG31)-Stamm gesehen werden.

Die Ergebnisse der vorliegenden Arbeit zeigen weiterhin, dass in Spv-1-(ArhGAP29-) knock-out-Würmern, verglichen mit Würmern des Wildtypstammes, die Anzahl der abgelegten Eier signifikant reduziert ist. Dies ist in Einklang mit den Daten von Tan und Zaidel-Bar, 2015, die ebenso in Spv-1 defizienten Würmern eine verminderte Eiablagemenge beschrieben haben. Im Fadenwurm ist Spv-1 an der Regulation des RhoA-Homologs im Wurm, RHO-1, beteiligt und beeinflusst so die Kontraktilität der Aktinfilamente, welche wiederum u.a. die Kontraktion der Spermathek und die Eiablage von C. elegans steuern (Shyn et al. 2003).

Auch für den HIF-defizienten Wurm wurde bereits eine verminderte Brutgröße gezeigt (Kamal et al. 2016), die in den in dieser Arbeit gezeigten Experimenten bestätigt werden konnte. Die möglicherweise HIF-1-abhängige Expression von Spv-1 könnte zu dieser verminderten Eiablagemenge beitragen.

Dieses Experiment verdeutlicht, dass auch in dem mehrzelligen Organismus C. elegans der Knock-out des ArhGAP29-homologen Gens Spv-1 zu funktionellen Veränderungen führt.

In Mäusen beschrieben Xu et al. außerdem eine Funktion von ArhGAP29 in der Embryonalentwicklung. ArhGAP29 und sein Bindungspartner Rasip1 sind essenzielle Faktoren für die Lumenbildung im Rahmen der Vaskulogenese in Mäuseembryos (Xu et al. 2011). Von 


\section{Diskussion}

Barry et al. erzeugte Mäuse mit ArhGAP29-knock-down starben bereits an Tag E9-E10 der Embryonalentwicklung durch Defekte in der Ausbildung der Plazenta. Außerdem zeigte sich bei ArhGAP29-knock-down eine verengte Aorta dorsalis (Barry et al. 2016).

\subsection{Die Rolle von ArhGAP29 in klinisch relevanten Pathologien}

Verschiedene Arbeiten beschreiben erhöhte oder erniedrigte ArhGAP29-Level auch bei Erkrankungen, die den Menschen betreffen. Von Leslie et al. wird ArhGAP29 im Zusammenhang mit einer embryologischen Entwicklungsstörung, der nichtsyndromalen Lippen- und Kieferspalte mit oder ohne Gaumenbeteiligung (LKGS) genannt (Leslie et al. 2012). Hierbei handelt es sich um eine embryonale Fehlbildung, bei der die Verschmelzung der zwei Nasen- und Oberkieferwülste zur Formung des Mittelgesichts nicht korrekt abläuft. In Mäuseembryos wurden an Tag E10.5 eine starke Expression von ArhGAP29 in der medialen und lateralen Nasenwulst nachgewiesen, was einen Einfluss des Proteins in der kraniofazialen Entwicklung nahelegt (Gritli-Linde 2008). Da in LKGS-Patienten Nonsens-Mutationen im ArhGAP29-Gen gefunden wurden und ihre Stammzellen eine dreifach verminderte Genexpression des ArhGAP29-Gens im Vergleich zu nicht betroffenen Probanden zeigten, scheint ein Mangel an ArhGAP29 eine nichtsyndromale LKGS zu begünstigen (Bueno et al. 2011; Leslie et al. 2012). Unabhängig von den oben genannten Befunden spricht auch die in dieser Arbeit nachgewiesene hypoxische Induktion von ArhGAP29 für eine Beteiligung des Proteins an der Embryogenese, da sich Embryonen in einem konstanten Zustand partieller Hypoxie befinden (Webster und Abela 2007).

In malignen Erkrankungen wird die Rolle von ArhGAP29 von verschiedenen Autoren vom Tumorsuppressorgen bis hin zum Protein mit karzinogener Wirkung beschrieben: Im humanen Genom fällt die Lokalisation des ArhGAP29-Gens auf Chromosom 1p22 und damit in einen Bereich, der in Mantelzelllymphomen häufig Mutationen aufweist. Hierbei handelt es sich um ein niedrigmalignes B-Zell-Non-Hodgkin-Lymphom. Ripperger et al. fanden eine deutlich verminderte Expression von ArhGAP29 in Zellen von Mantelzelllymphomen und beschrieben es als mögliches Tumorsuppressorgen (Ripperger et al. 2007).

Im Gegensatz dazu wurde eine Überexpression von ArhGAP29 in Glioblastomzellen (Mariani et al. 2001) sowie in Zellen des Nierenzellkarzinoms beschrieben. Es konnte nachgewiesen werden, dass eine höhere ArhGAP29-Expression mit einer stärkeren Invasionsfähigkeit und Zellproliferation beim Nierenzellkarzinom einhergeht. Außerdem stellt das ArhGAP29-Level in den Zellen eines Nierenzellkarzinoms einen unabhängigen Prognosefaktor für das 


\section{Diskussion}

Wiederauftreten der Erkrankung dar (Miyazaki et al. 2017). Eine starke Expression von ArhGAP29 in Tumorzellen könnten ihre Ursache in der von mir gezeigten hypoxischen Induktion des ArhGAP29-Gens haben, da in wachsenden Tumoren regelhaft hypoxische Bedingungen mit Stabilisierung von HIF-1 $\alpha$ herrschen (Zhong et al. 1999).

Die genannten Pathologien, in denen ArhGAP29 bislang durch hohe oder niedrige Proteinlevel hervorstach, sind die Tumorbildung sowie Defekte in der Embryogenese. Gemeinsamer Nenner dieser Leiden ist die hypoxische Umgebung, in der sich die Erkrankungen entwickeln. $\mathrm{Ob}$ ArhGAP29 in der Tumorgenese einen vorwiegend benignen oder malignen Effekt ausmacht, bleibt in zukünftigen Arbeiten zu diesem Thema abzuwarten.

\subsection{Ausblick}

In dieser Arbeit wurde mit ArhGAP29 ein Protein als Hypoxie-abhängig identifiziert, das als RhoA-Regulator die Dynamik des Aktinzytoskeletts in Normoxie und Hypoxie beeinflusst. Die festgestellte hypoxische Induktion von ArhGAP29 macht es wahrscheinlich, dass die unter Hypoxie wahrgenommenen Veränderungen der Aktindynamik zumindest teilweise über ArhGAP29 vermittelt werden. Zwar konnte in dieser Arbeit gezeigt werden, dass ArhGAP29 abhängig von HIF-1 gebildet wird, der Beweis einer direkten Bindung des Transkriptionsfaktors an die Promotorregion von ArhGAP29 steht allerdings noch aus. Anhand eines Chromatin-Immunopräzipitations- (ChIP)-Assays könnte bestimmt werden, ob es sich bei ArhGAP29 um eines der direkten Zielgene von HIF-1 handelt. Des Weiteren wäre die Durchführung eines EMSA (Electrophoretic Mobility Shift Assay) sinnvoll, um eine ProteinDNA-Interaktion von HIF-1 und der Promotorregion des ArhGAP29-Gens zu analysieren. In weiteren Experimenten an ArhGAP29-knock-down-Zellen wäre es interessant zu überprüfen, ob entsprechend der Annahme die RhoA-Aktivität in Normoxie und Hypoxie zunimmt. 


\section{Zusammenfassung}

Wenn sich Zellen in Hypoxie befinden, aktivieren sie zahlreiche Anpassungsmechanismen, die vor allem einer verbesserten Sauerstoffversorgung des Gewebes dienen. Diese werden meist über HIF-1, den Haupttranskriptionsfaktor unter hypoxischen Bedingungen, vermittelt. In hypoxischen L929-Fibroblasten wurden darüber hinaus Effekte beobachtet, die auf eine veränderte Aktindynamik schließen lassen, hierzu zählen Veränderungen der Zellfläche, des Spreadings, der Migration und die vermehrte Ausbildung von stress fibres. Derartige Modifikationen des Aktinzytoskeletts werden durch kleine Rho-GTPasen, wie z.B. RhoA, reguliert. Während in der Literatur eine hypoxische Aktivitätsänderung von RhoA vielfach diskutiert wurde, gab es kaum Untersuchungen zu der Frage, wie sich die Rho-regulierenden Proteine, die GEFs, GAPS und GDIs, unter Hypoxie verhalten. Durch dieses Regulationssystem, in dem Rho-GTPasen durch GEFs aktiviert und durch GAPs und GDIs inaktiviert bzw. inaktiviert im Zytosol gehalten werden, wird die Aktivität von Rho-GTPasen genau kontrolliert.

Nach Expressionsanalyse mehrerer GAPs und GEFs konnte in dieser Arbeit für einen Vertreter der GAPs, nämlich das Rho-GTPase-aktivierende-Protein 29 (ArhGAP29), in L929Fibroblasten eine hypoxische Induktion auf mRNA- sowie Proteinebene nachgewiesen werden. In einem weiteren Versuch bestätigte sich die Vermutung, dass diese hypoxische Induktion abhängig von HIF-1 $\alpha$ geschieht. Auch in C2C12-Myoblasten zeigte sich ein erhöhtes ArhGAP29-mRNA-Level in Hypoxie, was für einen zelllinienübergreifenden Mechanismus spricht. ArhGAP29 hemmt mit seiner GAP-Domäne die RhoA-Aktivität und wirkt damit beispielsweise der Ausbildung von Aktinfilamenten und Zellkontraktilität entgegen. Da in L929-Fibroblasten in Hypoxie ein zeitlicher Verlauf der RhoA-Aktivität mit früher Zunahme, gefolgt von einer Abnahme der Aktivität, welche parallel zur gesteigerten ArhGAP29Expression erfolgte, zu beobachten war, lässt sich die Funktion von ArhGAP29 am ehesten als Feinregulation der RhoA-Aktivität in Normoxie und Hypoxie deuten. Zellklone mit stabilem Knock-down des ArhGAP29-Gens zeigten bereits in Normoxie bemerkenswerte morphologische Veränderungen, wie eine Zunahme der Zellfläche und die vermehrte Ausbildung von stress fibres, was durch eine erhöhte RhoA-Aktivität erklärt werden kann. In weiteren Experimenten am Nematoden C. elegans ließ sich eine hypoxische Induktion des ArhGAP29-homologen Gens Spv-1 nachweisen; zusätzlich war die Zahl gelegter Eier pro Zeiteinheit von C.elegans-Würmern mit Knock-out von Spv-1 im Vergleich zu Wildtypwürmern signifikant reduziert. Eine fehlende Expression des ArhGAP29 homologen 
Zusammenfassung

Spv-1-Gens führt also auch in mehrzelligen Organismen zu schwerwiegenden funktionellen Veränderungen, die auf Modulationen der Aktinfilamentorganisation zurückzuführen sein könnten.

Defekte des ArhGAP29-Gens werden in der Literatur unter anderem im Zusammenhang mit embryogenetischen Störungen genannt. Dazu zählt eine gestörte Lumenbildung während der Vaskulogenese in Mäuseembryos sowie eine Assoziation mit der Lippen-Kiefer(Gaumen-) Spalte im Menschen. Im Rahmen maligner Erkrankungen wird ArhGAP29 kontrovers diskutiert. Je nach Tumorentität sind Hinweise auf eine Funktion als Tumorsuppressorgen, aber auch auf eine karzinogene Wirkung von ArhGAP29 gefunden worden. Die genannten Krankheitsbilder passen zu der in dieser Arbeit nachgewiesenen hypoxischen Induktion von ArhGAP29, da sowohl die Embryogenese als auch die Tumorgenese regelhaft mit Zuständen der Hypoxie einhergehen.

Zur weiteren Klärung der Expressionsregulation von ArhGAP29 in Hypoxie wäre die Durchführung eines Chromatin-Immunopräzipitations- (ChIP-) Assays und eines EMSA (Electrophoretic Mobility Shift Assay) sinnvoll, um eine direkte Bindung des Transkriptionsfaktors HIF-1 an den Promotor des ArhGAP29-Gens nachzuweisen. Außerdem sollte überprüft werden, ob die RhoA-Aktivität in ArhGAP29-knock-down-Zellen in Normoxie und Hypoxie zunimmt. 


\section{Literaturverzeichnis}

Appelhoff RJ, Tian YM, Raval RR, Turley H, Harris AL, Pugh CW, Ratcliffe PJ, Gleadle JM (2004), Differential function of the prolyl hydroxylases PHD1, PHD2, and PHD3 in the regulation of hypoxia-inducible factor. J Biol Chem 279(37), 38458-38465

Bailly K, Ridley AJ, Hall SM, Haworth SG (2004), RhoA activation by hypoxia in pulmonary arterial smooth muscle cells is age and site specific. Circ Res 94(10), 1383-1391

Barry DM, Koo Y, Norden PR, Wylie LA, Xu K, Wichaidit C, Azizoglu DB, Zheng Y, Cobb MH, Davis GE, Cleaver O (2016), Rasip1-Mediated Rho GTPase Signaling Regulates Blood Vessel Tubulogenesis via Nonmuscle Myosin II. Circ Res 119(7), 810-826

Berra E, Benizri E, Ginouves A, Volmat V, Roux D, Pouyssegur J (2003), HIF prolylhydroxylase 2 is the key oxygen sensor setting low steady-state levels of HIF-1alpha in normoxia. EMBO J 22(16), 4082-4090

Bos JL, Rehmann H, Wittinghofer A (2007), GEFs and GAPs: critical elements in the control of small G proteins. Cell $\underline{129}(5), 865-877$

Brillault J, Lam TI, Rutkowsky JM, Foroutan S, O'Donnell ME (2008), Hypoxia effects on cell volume and ion uptake of cerebral microvascular endothelial cells. Am J Physiol Cell Physiol 294(1), C88-96

Brown SS, Spudich JA (1979), Nucleation of polar actin filament assembly by a positively charged surface. J Cell Biol $\underline{\text { 80}(2), ~ 499-504 ~}$

Bueno DF, Sunaga DY, Kobayashi GS, Aguena M, Raposo-Amaral CE, Masotti C, Cruz LA, Pearson PL, Passos-Bueno MR (2011), Human stem cell cultures from cleft lip/palate patients show enrichment of transcripts involved in extracellular matrix modeling by comparison to controls. Stem Cell Rev $\underline{7}(2), 446-457$

Cerione RA, Zheng Y (1996), The Dbl family of oncogenes. Curr Opin Cell Biol $\underline{8}(2), 216-222$

Cherfils J, Zeghouf M (2013), Regulation of small GTPases by GEFs, GAPs, and GDIs. Physiol Rev 93(1), 269-309

Cioffi CL, Liu XQ, Kosinski PA, Garay M, Bowen BR (2003), Differential regulation of HIF1 alpha prolyl-4-hydroxylase genes by hypoxia in human cardiovascular cells. Biochem Biophys Res Commun 303(3), 947-953

Ebert BL, Firth JD, Ratcliffe PJ (1995), Hypoxia and mitochondrial inhibitors regulate expression of glucose transporter-1 via distinct Cis-acting sequences. J Biol Chem $\underline{\text { 270 }}$ (49), 29083-29089

Ema M, Taya S, Yokotani N, Sogawa K, Matsuda Y, Fujii-Kuriyama Y (1997), A novel bHLHPAS factor with close sequence similarity to hypoxia-inducible factor 1alpha regulates the VEGF expression and is potentially involved in lung and vascular development. Proc Natl Acad Sci U S A 94(9), 4273-4278

Etienne-Manneville S, Hall A (2002), Rho GTPases in cell biology. Nature 420(6916), 629635

Evans AJ, Russell RC, Roche O, Burry TN, Fish JE, Chow VW, Kim WY, Saravanan A, Maynard MA, Gervais ML, Sufan RI, Roberts AM, Wilson LA, Betten M, Vandewalle C, Berx G, Marsden PA, Irwin MS, Teh BT, Jewett MA, Ohh M (2007), VHL promotes E2 box-dependent E-cadherin transcription by HIF-mediated regulation of SIP1 and snail. Mol Cell Biol 27(1), 157-169 
Forsythe JA, Jiang BH, Iyer NV, Agani F, Leung SW, Koos RD, Semenza GL (1996), Activation of vascular endothelial growth factor gene transcription by hypoxiainducible factor 1. Mol Cell Biol 16(9), 4604-4613

Gilkes DM, Xiang L, Lee SJ, Chaturvedi P, Hubbi ME, Wirtz D, Semenza GL (2014), Hypoxiainducible factors mediate coordinated RhoA-ROCK1 expression and signaling in breast cancer cells. Proc Natl Acad Sci U S A 111(3), E384-393

Gritli-Linde A (2008), The etiopathogenesis of cleft lip and cleft palate: usefulness and caveats of mouse models. Curr Top Dev Biol 4ㅜ, 37-138

Hall A (1998), Rho GTPases and the actin cytoskeleton. Science 279(5350), 509-514

Hall A (2012), Rho family GTPases. Biochem Soc Trans 40(6), 1378-1382

Heasman SJ, Ridley AJ (2008), Mammalian Rho GTPases: new insights into their functions from in vivo studies. Nat Rev Mol Cell Biol 9(9), 690-701

Hirsila M, Koivunen P, Gunzler V, Kivirikko KI, Myllyharju J (2003), Characterization of the human prolyl 4-hydroxylases that modify the hypoxia-inducible factor. J Biol Chem $\underline{278(33), 30772-30780}$

Holmes KC, Popp D, Gebhard W, Kabsch W (1990), Atomic model of the actin filament. Nature $\underline{347}(6288), 44-49$

Hu CJ, Wang LY, Chodosh LA, Keith B, Simon MC (2003), Differential roles of hypoxiainducible factor 1alpha (HIF-1alpha) and HIF-2alpha in hypoxic gene regulation. Mol Cell Biol 23(24), 9361-9374

Ivan M, Kondo K, Yang H, Kim W, Valiando J, Ohh M, Salic A, Asara JM, Lane WS, Kaelin WG, Jr. (2001), HIFalpha targeted for VHL-mediated destruction by proline hydroxylation: implications for O2 sensing. Science 292(5516), 464-468

Iyer NV, Kotch LE, Agani F, Leung SW, Laughner E, Wenger RH, Gassmann M, Gearhart JD, Lawler AM, Yu AY, Semenza GL (1998), Cellular and developmental control of O2 homeostasis by hypoxia-inducible factor 1 alpha. Genes Dev $\underline{12}(2), 149-162$

Jaakkola P, Mole DR, Tian YM, Wilson MI, Gielbert J, Gaskell SJ, von Kriegsheim A, Hebestreit HF, Mukherji M, Schofield CJ, Maxwell PH, Pugh CW, Ratcliffe PJ (2001), Targeting of HIF-alpha to the von Hippel-Lindau ubiquitylation complex by O2regulated prolyl hydroxylation. Science 292(5516), 468-472

Jiang BH, Zheng JZ, Leung SW, Roe R, Semenza GL (1997), Transactivation and inhibitory domains of hypoxia-inducible factor 1alpha. Modulation of transcriptional activity by oxygen tension. J Biol Chem 272(31), 19253-19260

Kaelin WG, Jr. (2002), Molecular basis of the VHL hereditary cancer syndrome. Nat Rev Cancer 2(9), 673-682

Kaibuchi K, Kuroda S and Amano M (1999), Regulation of the cytoskeleton and cell adhesion by the Rho family GTPases in mammalian cells. Annu Rev Biochem $\underline{68}$, 459-486

Kallio PJ, Okamoto K, O'Brien S, Carrero P, Makino Y, Tanaka H, Poellinger L (1998), Signal transduction in hypoxic cells: inducible nuclear translocation and recruitment of the $\mathrm{CBP} / \mathrm{p} 300$ coactivator by the hypoxia-inducible factor-1alpha. EMBO J 17(22), 65736586

Kamal M, D'Amora DR, Kubiseski TJ (2016), Loss of hif-1 promotes resistance to the exogenous mitochondrial stressor ethidium bromide in Caenorhabditis elegans. BMC Cell Biol 17 Suppl 1, 34 
Kayyali US, Pennella CM, Trujillo C, Villa O, Gaestel M, Hassoun PM (2002), Cytoskeletal changes in hypoxic pulmonary endothelial cells are dependent on MAPK-activated protein kinase MK2. J Biol Chem 277(45), 42596-42602

Lando D, Peet DJ, Gorman JJ, Whelan DA, Whitelaw ML, Bruick RK (2002), FIH-1 is an asparaginyl hydroxylase enzyme that regulates the transcriptional activity of hypoxiainducible factor. Genes Dev $\underline{16}(12), 1466-1471$

Latif F, Tory K, Gnarra J, Yao M, Duh FM, Orcutt ML, Stackhouse T, Kuzmin I, Modi W, Geil L (1993), Identification of the von Hippel-Lindau disease tumor suppressor gene. Science 260(5112), 1317-1320

Leslie EJ, Mansilla MA, Biggs LC, Schuette K, Bullard S, Cooper M, Dunnwald M, Lidral AC, Marazita ML, Beaty TH, Murray JC (2012), Expression and mutation analyses implicate ARHGAP29 as the etiologic gene for the cleft lip with or without cleft palate locus identified by genome-wide association on chromosome 1p22. Birth Defects Res A Clin Mol Teratol 94(11), 934-942

Lieb ME, Menzies K, Moschella MC, Ni R, Taubman MB (2002), Mammalian EGLN genes have distinct patterns of mRNA expression and regulation. Biochem Cell Biol $\underline{80}(4)$, $421-426$

Liu W, Shen SM, Zhao XY, Chen GQ (2012), Targeted genes and interacting proteins of hypoxia inducible factor-1. Int J Biochem Mol Biol $\underline{3}(2), 165-178$

Maekawa M, Ishizaki T, Boku S, Watanabe N, Fujita A, Iwamatsu A, Obinata T, Ohashi K, Mizuno K, Narumiya S (1999), Signaling from Rho to the actin cytoskeleton through protein kinases ROCK and LIM-kinase. Science 285(5429), 895-898

Mahon PC, Hirota K, Semenza GL (2001), FIH-1: a novel protein that interacts with HIF1alpha and VHL to mediate repression of HIF-1 transcriptional activity. Genes Dev $\underline{15}(20), 2675-2686$

Mariani L, Beaudry C, McDonough WS, Hoelzinger DB, Demuth T, Ross KR, Berens T, Coons SW, Watts G, Trent JM, Wei JS, Giese A, Berens ME (2001), Glioma cell motility is associated with reduced transcription of proapoptotic and proliferation genes: a cDNA microarray analysis. J Neurooncol 53(2), 161-176

Matsui T, Amano M, Yamamoto T, Chihara K, Nakafuku M, Ito M, Nakano T, Okawa K, Iwamatsu A, Kaibuchi K (1996), Rho-associated kinase, a novel serine/threonine kinase, as a putative target for small GTP binding protein Rho. EMBO J 15(9), 22082216

Maxwell PH, Wiesener MS, Chang GW, Clifford SC, Vaux EC, Cockman ME, Wykoff CC, Pugh CW, Maher ER, Ratcliffe PJ (1999), The tumour suppressor protein VHL targets hypoxia-inducible factors for oxygen-dependent proteolysis. Nature 399(6733), 271275

Melillo G, Musso T, Sica A, Taylor LS, Cox GW, Varesio L (1995), A hypoxia-responsive element mediates a novel pathway of activation of the inducible nitric oxide synthase promoter. J Exp Med 182(6), 1683-1693

Metzen E, Berchner-Pfannschmidt U, Stengel P, Marxsen JH, Stolze I, Klinger M, Huang WQ, Wotzlaw C, Hellwig-Burgel T, Jelkmann W, Acker H, Fandrey J (2003), Intracellular localisation of human HIF-1 alpha hydroxylases: implications for oxygen sensing. J Cell Sci $\underline{116}(\mathrm{Pt} 7), 1319-1326$ 
Mitchison TJ (1995), Evolution of a dynamic cytoskeleton. Philos Trans R Soc Lond B Biol Sci $\underline{349}$ (1329), 299-304

Miyazaki J, Ito K, Fujita T, Matsuzaki Y, Asano T, Hayakawa M, Kawakami Y (2017), Progression of Human Renal Cell Carcinoma via Inhibition of RhoA-ROCK Axis by PARG1. Transl Oncol 10(2), 142-152

Mizuno K (2013), Signaling mechanisms and functional roles of cofilin phosphorylation and dephosphorylation. Cell Signal 25(2), 457-469

Myllyla R, Kuutti-Savolainen ER, Kivirikko KI (1978), The role of ascorbate in the prolyl hydroxylase reaction. Biochem Biophys Res Commun $\underline{83}(2), 441-448$

Narumiya S, Ishizaki T, Watanabe N (1997), Rho effectors and reorganization of actin cytoskeleton. FEBS Lett $\underline{410}(1), 68-72$

Norris ML, Millhorn DE (1995), Hypoxia-induced protein binding to O2-responsive sequences on the tyrosine hydroxylase gene. J Biol Chem 270(40), 23774-23779

Olofsson B (1999), Rho guanine dissociation inhibitors: pivotal molecules in cellular signalling. Cell Signal 11(8), 545-554

Perrin BJ, Ervasti JM (2010), The actin gene family: function follows isoform. Cytoskeleton (Hoboken) 67(10), 630-634

Pollard TD, Cooper JA (2009), Actin, a central player in cell shape and movement. Science 326(5957), 1208-1212

Post A, Pannekoek WJ, Ross SH, Verlaan I, Brouwer PM, Bos JL (2013), Rasip1 mediates Rap1 regulation of Rho in endothelial barrier function through ArhGAP29. Proc Natl Acad Sci U S A $\underline{110}(28), 11427-11432$

Post A, Pannekoek WJ, Ponsioen B, Vliem MJ, Bos JL (2015), Rap1 spatially controls ArhGAP29 to inhibit Rho signaling during endothelial barrier regulation. Mol Cell Biol 35(14), 2495-502

Reinhard NR, van Helden SF, Anthony EC, Yin T, Wu YI, Goedhart J, Gadella TW, Hordijk PL (2016), Spatiotemporal analysis of RhoA/B/C activation in primary human endothelial cells. Sci Rep $\underline{6}, 25502$

Reisz-Porszasz S, Probst MR, Fukunaga BN, Hankinson O (1994), Identification of functional domains of the aryl hydrocarbon receptor nuclear translocator protein (ARNT). Mol Cell Biol 14(9), 6075-6086

Ridley AJ (2001), Rho family proteins: coordinating cell responses. Trends Cell Biol 11(12), 471-477

Ridley AJ, Hall A (1992), The small GTP-binding protein rho regulates the assembly of focal adhesions and actin stress fibers in response to growth factors. Cell 70(3), 389-399

Ripperger T, von Neuhoff N, Kamphues K, Emura M, Lehmann U, Tauscher M, Schraders M, Groenen P, Skawran B, Rudolph C, Callet-Bauchu E, van Krieken JH, Schlegelberger B, Steinemann D (2007), Promoter methylation of PARG1, a novel candidate tumor suppressor gene in mantle-cell lymphomas. Haematologica 92(4), 460-468

Robertson AS, Smythe E, Ayscough KR (2009), Functions of actin in endocytosis. Cell Mol Life Sci 66(13), 2049-2065

Rocha S (2007), Gene regulation under low oxygen: holding your breath for transcription.

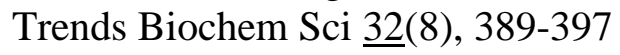


Rutkowsky JM, Wallace BK, Wise PM, O'Donnell ME (2011), Effects of estradiol on ischemic factor-induced astrocyte swelling and AQP4 protein abundance. Am J Physiol Cell Physiol 301(1), C204-212

Sahai E, Marshall CJ (2002), RHO-GTPases and cancer. Nat Rev Cancer 22(2), 133-142

Saras J, Franzen P, Aspenstrom P, Hellman U, Gonez LJ, Heldin CH (1997), A novel GTPaseactivating protein for Rho interacts with a PDZ domain of the protein-tyrosine phosphatase PTPL1. J Biol Chem 272(39), 24333-24338

Schiltz RL, Mizzen CA, Vassilev A, Cook RG, Allis CD, Nakatani Y (1999), Overlapping but distinct patterns of histone acetylation by the human coactivators $\mathrm{p} 300$ and PCAF within nucleosomal substrates. J Biol Chem 274(3), 1189-1192

Shyn SI, Kerr R, Schafer WR (2003), Serotonin and Go modulate functional states of neurons and muscles controlling C. elegans egg-laying behavior. Curr Biol 13(21), 1910-1915

Skalli O, Schurch W, Seemayer T, Lagace R, Montandon D, Pittet B, Gabbiani G (1989), Myofibroblasts from diverse pathologic settings are heterogeneous in their content of actin isoforms and intermediate filament proteins. Lab Invest $\underline{60}(2), 275-285$

Tan PY, Zaidel-Bar R (2015), Transient membrane localization of SPV-1 drives cyclical actomyosin contractions in the C. elegans spermatheca. Curr Biol 25(2), 141-151

Tcherkezian J, Lamarche-Vane N (2007), Current knowledge of the large RhoGAP family of proteins. Biol Cell 99(2), 67-86

Theriot JA (2000), The polymerization motor. Traffic $\underline{1}(1), 19-28$

Tojkander S, Gateva G, Lappalainen P (2012), Actin stress fibers--assembly, dynamics and biological roles. J Cell Sci $\underline{125}(\mathrm{Pt}$ 8), 1855-1864

Vavylonis D, Yang Q, O'Shaughnessy B (2005), Actin polymerization kinetics, cap structure, and fluctuations. Proc Natl Acad Sci U S A 102(24), 8543-8548

Vega FM, Ridley AJ (2008), Rho GTPases in cancer cell biology. FEBS Lett 582(14), 20932101

Vogler M, Vogel S, Krull S, Farhat K, Leisering P, Lutz S, Wuertz CM, Katschinski DM, Zieseniss A (2013), Hypoxia modulates fibroblastic architecture, adhesion and migration: a role for HIF-1alpha in cofilin regulation and cytoplasmic actin distribution. PLoS One $\underline{8}(7)$, e69128

Wang GL, Semenza GL (1993), Characterization of hypoxia-inducible factor 1 and regulation of DNA binding activity by hypoxia. J Biol Chem 268(29), 21513-21518

Wang GL, Jiang BH, Rue EA, Semenza GL (1995), Hypoxia-inducible factor 1 is a basic-helixloop-helix-PAS heterodimer regulated by cellular O2 tension. Proc Natl Acad Sci U S A $\underline{92}(12), 5510-5514$

Wang Z, Jin N, Ganguli S, Swartz DR, Li L, Rhoades RA (2001), Rho-kinase activation is involved in hypoxia-induced pulmonary vasoconstriction. Am J Respir Cell Mol Biol $\underline{25}(5), 628-635$

Webster WS, Abela D (2007), The effect of hypoxia in development. Birth Defects Res C Embryo Today 81(3), 215-228 


\section{Literaturverzeichnis}

Wiesener MS, Jurgensen JS, Rosenberger C, Scholze CK, Horstrup JH, Warnecke C, Mandriota S, Bechmann I, Frei UA, Pugh CW, Ratcliffe PJ, Bachmann S, Maxwell PH, Eckardt KU (2003), Widespread hypoxia-inducible expression of HIF-2alpha in distinct cell populations of different organs. FASEB J 17(2), 271-273

Willam C, Maxwell PH, Nichols L, Lygate C, Tian YM, Bernhardt W, Wiesener M, Ratcliffe PJ, Eckardt KU, Pugh CW (2006), HIF prolyl hydroxylases in the rat; organ distribution and changes in expression following hypoxia and coronary artery ligation. J Mol Cell Cardiol $\underline{41}(1), 68-77$

Xu K, Sacharidou A, Fu S, Chong DC, Skaug B, Chen ZJ, Davis GE, Cleaver O (2011), Blood vessel tubulogenesis requires Rasip1 regulation of GTPase signaling. Dev Cell 20(4), 526-539

Yu F, White SB, Zhao Q, Lee FS (2001), HIF-1alpha binding to VHL is regulated by stimulussensitive proline hydroxylation. Proc Natl Acad Sci U S A $\underline{98}(17), 9630-9635$

Zhong H, De Marzo AM, Laughner E, Lim M, Hilton DA, Zagzag D, Buechler P, Isaacs WB, Semenza GL, Simons JW (1999), Overexpression of hypoxia-inducible factor 1alpha in common human cancers and their metastases. Cancer Res $\underline{59}(22), 5830-5835$

Zieseniss A (2014), Hypoxia and the modulation of the actin cytoskeleton - emerging interrelations. Hypoxia 2014(2), 11-21 


\section{Danksagung}

Ich bedanke mich sehr herzlich bei meiner Doktormutter Frau Prof. Dr. med. D. M. Katschinski für die Überlassung des Themas und die fortwährende Unterstützung während und nach meiner Zeit im Labor. Vielen Dank für die hilfreichen Überlegungen zur Ausführung dieses Projektes und für die gute Zusammenarbeit.

Besonders möchte ich den hervorragenden Einsatz meiner Betreuerin Frau Dr. rer. nat. Anke Zieseniß betonen, die das Projekt maßgeblich gestaltet hat und jederzeit vor, während und nach den praktischen Versuchen für mich ansprechbar war. Sie half mir mit viel Geduld und höchster Kompetenz bei der wissenschaftlichen Arbeit. Vielen Dank für die ausgezeichnete Betreuung und Begleitung dieser Arbeit!

Außerdem möchte ich mich ausdrücklich bei Frau Sabine Krull bedanken, die mir mit großer Geduld und Freundlichkeit den größten Teil aller im Labor verwendeten Methoden beibrachte. Sie hatte stets ein offenes Ohr, wusste immer zu helfen und unterstützte besonders die praktischen Teile der Arbeit tatkräftig.

Weiterhin danke ich Frau Melanie Vogler für die Einführung in das Programm ImageJ und für das Zurverfügungstellen ihrer Zellreihen. Frau Dr. Liza Swain möchte ich für die Erläuterung des Auswertungsprogramms Graph Pad danken.

Ich danke weiterhin allen Mitarbeitern der Herz-Kreislaufphysiologie für die nette Aufnahme im Team und Unterstützungen aller Art: Frau Dr. rer. nat. Amke Hesse, Frau Dr. rer. nat. Marieke Wottawa, Frau Dr. rer. nat. Christina Würtz, Frau Annette Hillemann, Frau Melanie von Ahlen, Frau Angelika Beneke, Frau Annemarie Güntsch.

Beim Deutschen Zentrum für Herz- Kreislaufforschung (DZHK) möchte ich mich herzlich für die Förderung im Rahmen eines Promotionsstipendiums bedanken. 